ПРИМЕНЕНИЕ РОТАЦИОННОЙ ТРОМБОЭЛАСТОМЕТРИИ ДЛЯ ДИАГНОСТИКИ ДЕФИЦИТА ФАКТОРОВ СВЕРТЫВАНИЯ И КОНТРОЛЯ ГЕМОСТАТИЧЕСКОЙ ТЕРАПИИ У БОЛЬНЫХ НАСЛЕДСТВЕННЫМИ КОАГУЛОПАТИЯМИ

Галстян Г. М. ${ }^{*}$ Полеводова О. А., Яковлева Е. В., Щекина А. Е.

ФГБУ «Национальный медицинский исследовательский центр гематологии» Министерства здравоохранения Российской Федерации

125167, Москва, Россия

\title{
PEЗЮME
}

Введение. Ротационная тромбоэластометрия (РОТЭМ) является методом исследования гемостаза, который выполняется по месту лечения и позволяет выявлять нарушения по внешнему и/или внутреннему пути свертывания крови.

Цель работы - изучить возможность использования РОТЭМ для диагностики дефицита отдельных факторов свертывания крови и мониторинга эффективности и безопасности гемостатической терапии, проводимой при этих коагулопатиях.

Материалы и методы. В исследование было включено 9 больных с врожденным дефицитом различных факторов свертывания крови. Проводили коагулогические тесты (определение активированного частичного тромбопластинового времени, протромбина по Квику, фибриногена, плазменной активности факторов свертывания FV, FVII, FVIII, FIX, FXI и FXII) и РОТЭМ. Для исключения влияния гепарина или гипофибриногенемии выполняли НEPTEM и/или FIBTEM. Для выявления дефицита отдельных факторов свертывания крови использовали образцы стандартной плазмы и плазмы, дефицитной по одному из факторов свертывания крови. Исследуемую цитратную кровь смешивали в соотношении 2:1 со стандартной плазмой и с дефицитной по одному из исследуемых факторов плазмой, повторно выполняли тесты EXTEM и/или INTEM. Дефицит фактора свертывания крови подтверждали по изменению параметра СТ.

Результаты. Изолированное удлинение СТ в тесте EXTEM выявлялось при дефиците FVII, удлинение СT только в INTEM возникало при дефиците FVIII, FIX, FXI, FXII, одновременное удлинение EXTEM и INTEM определялось при дефиците FV. При выполнении пробы со смесью цитратной крови и стандартной плазмы параметр СТ укорачивался в тесте EXTEM при дефиците FVII, в тесте INTEM - при дефиците FVIII, FIX, FXI, FXII, в обоих тестах - при дефиците FV. В пробе со смесью цельной крови и дефицитной по исследуемому фактору плазмой интервал СТ сохранялся удлиненным либо увеличивался. Приведены клинические примеры диагностики дефицита факторов свертывания с помощью РОТЭМ.

Заключение. Нормализация показателей РОТЭМ в пробе со стандартной плазмой и сохранение гипокоагуляции в пробе с дефицитной по фактору плазмой позволяет подтвердить дефицит фактора свертывания крови. С помощью РОТЭМ возможно проведение мониторинга эффективности гемостатической терапии при врожденных дефицитах отдельных факторов свертывания крови.

Ключевые слова: ротационная тромбоэластометрия, дефицит факторов свертывания, наследственная коагулопатия

Конфликт интересов: авторы заявляют об отсутствии конфликта интересов.

Финансирование: исследование не имело спонсорской поддержки.

Для цитирования: Галстян Г.М., Полеводова О.А., Яковлева Е.В., Щекина А.Е. Применение ротационной тромбоэластометрии для диагностики дефицита факторов свертывания и контроля гемостатической терапии у больных наследственными коагулопатиями. Гематология и трансфузиология. 2019; 64(3):297-316. https://doi.org/10.35754/0234-5730-2019-64-3-297-316 


\section{ROTATION THROMBOELASTOMETRY FOR THE DIAGNOSIS OF FACTOR DEFICIENCY AND MANAGEMENT OF THE HEMOSTATIC THERAPY IN PATIENTS WITH INHERITED COAGULATION DISORDERS}

Galstyan G. M. ${ }^{*}$, Polevodova O. A., Yakovleva E. V., Shchekina A. E. National Research Center for Hematology, 125167, Moscow, Russian Federation

\section{ABSTRACT}

Introduction. Rotation thromboelastometry (ROTEM) is a method for studying haemostasis at the place of providing care, which allows identification of disorders on the basis of extrinsic and / or intrinsic coagulation pathways.

Aim. To study the possibility of using ROTEM for diagnosing the deficiency of individual blood coagulation factors, as well as for monitoring the efficacy and safety of haemostatic therapy in such coagulopathies.

Materials and methods. The study included 9 patients with a congenital deficiency in various coagulation factors. The authors performed ROTEM, as well as coagulological tests to determine activated partial thromboplastin time, Quick's value, fibrinogen and the plasma activity of coagulation factors FV, FVII, FVIII, FIX, FXI and FXII. In order to exclude the effects of heparin or hyperfibrinogenaemia, HEPTEM and / or FIBTEM were conducted. In order to identify the deficiency of individual coagulation factors, the authors used standard plasma samples and plasma deficient in one of the coagulation factors. The citrated blood under study was mixed with standard plasma and that deficient in one of the studied factors in a 2:1 ratio for subsequent repetition of the EXTEM and / or INTEM tests. Coagulation factor deficiency was confirmed by a change in the CT parameter.

Results. Isolated prolongation of EXTEM CT was detected in the setting of FVII deficiency; while INTEM CT prolongation occurred under the deficiency of FVIII, FIX, FXI, FXII, with simultaneous EXTEM and INTEM CT prolongation being observed in the context of FVII deficiency. The test of a mixture of citrated blood and standard plasma revealed shortened EXTEM CT in the setting of FVII deficiency and shortened INTEM CT under the deficiency of FVIII, FIX, FXI, FXII, with the shortening of both EXTEM and INTEM CT being detected in the setting of FV deficiency. In a sample containing a mixture of whole blood and plasma deficient in the studied factor, CT remained prolonged or increased. Clinical examples of using ROTEM for diagnosing coagulation factor deficiency are presented.

Conclusion. The normalisation of ROTEM parameters in a standard plasma sample along with the preservation of hypocoagulation in a factor-deficient plasma sample confirms the coagulation factor deficiency. ROTEM provides the possibility of monitoring the efficacy of haemostatic therapy for congenital deficiencies in individual blood coagulation factors.

Keywords: rotation thromboelastometry, inherited coagulopathy, coagulation factor deficiency

Conflict of interest: the authors declare no conflict of interest.

Financial disclosure: the study had no sponsorship.

For citation: Galstyan G.M., Polevodova O.A., Yakovleva E.V., Shchekina A. E. Rotation thromboelastometry for the diagnosis of factor deficiency and management of the hemostatic therapy in patients with inherited coagulation disorders. Russian Journal of Hematology and Transfusiology (Gematologiya i transfuziologiya). 2019; 64(3):297-316 (in Russian). https://doi.org/10.35754/0234-5730-2019-64-3-297-316 


\section{Введение}

Ротационная тромбоэластометрия (РОТЭМ) позволяет оценить нарушения гемостаза у больных в критических состояниях, выбрать тот или иной метод лечения, мониторировать его эффективность [1]. РОТЭМ является point-of-care тестированием, т.е. исследованием, которое проводится по месту лечения, медицинским персоналом, не имеющим лабораторного образования [2]. Для его выполнения не требуется центрифугировать кровь, а результаты могут быть получены в течение короткого промежутка времени. В отличие от традиционных коагулогических тестов, с помощью РОТЭМ оценивают не активность отдельных факторов свертывающей или противосвертывающей систем, а систему гемостаза в целом как результат взаимодействия этих факторов [3]. Метод позволяет графически представить процесс образования и лизиса сгустка и с помощью соответствующих активаторов дифференцированно оценивать внешний и внутренний пути свертывания крови. В тесте INTEM после предварительной рекальцификации с помощью реагента star-tem добавляется реактив in-TEM, содержащий фосфолипиды, выделенные из мозга кроликов, и эллаговую кислоту. То есть, по сути, это реагент активированного частичного тромбопластинового времени (АЧТВ), инициирующий внутренний путь свертывания. Таким образом, в тесте INTEM свертывание по внутреннему пути запускается эллаговой кислотой на фосфолипидах, введенных в образец крови. В тесте EXTEM после реагента startem добавляется реактив ех-ТЕМ, содержащий фосфолипиды, тканевой фактор, запускающий свертывание по внешнему пути, и гепариназу, которая нивелирует возможное действие присутствующего гепарина. Таким образом, тесты EXTEM и INTEM можно использовать как скрининг для выявления нарушений свертывания крови по внешнему и/или внутреннему путям свертывания. При выявлении гипокоагуляции в тесте INTEM можно с помощью теста НЕРТЕМ исключить или подтвердить действие гепарина. При наличии в крови гепарина гипокоагуляция будет устранена добавлением гепариназы, при дефиците факторов свертывания крови она сохранится. Дефицит фактора, который привел к гипокоагуляции, выясняется обычно с помощью коагулогических тестов, при которых количественно оценивается активность факторов в плазме крови. Однако далеко не во всех стационарах есть лаборатории, которые могут определять дефицит отдельных факторов свертывания, прежде всего при врожденных коагулопатиях. Подобные больные, поступая в стационар для планового или экстренного хирургического вмешательства или в связи с геморрагическим синдромом, часто либо не получают адекватной помощи и перенаправляются в другие специализированные стационары, либо их лечат трансфузиями плазмы, которые не всегда эффективны.
Простота, удобство и информативность вискоэластичных методов оценки гемостаза способствовали их широкому распространению в клинической практике. Они востребованы для выявления нарушений гемостаза и мониторинга проводимой гемостатической терапии в акушерстве и гинекологии [4-6], интенсивной терапии и анестезиологии [7-10], сердечно-сосудистой хирургии [11-14], травматологии [15-18], при трансплантации печени $[1,19,20]$. Учитывая их большое значение, приказом Министерства здравоохранения Российской Федерации от 15 ноября 2012 г. № 919н регламентировано обязательное наличие тромбоэластографа или тромбоэластометра в отделениях анестезиологии-реаниматологии [21].

В этой связи представляется актуальным адаптировать метод РОТЭМ, доступный в большинстве стационаров, для определения дефицита отдельных факторов свертывания крови и мониторинга проводимой целенаправленной гемостатической терапии.

Цель настоящей работы - изучить возможность использования ротационной тромбоэластометрии для диагностики врожденного дефицита отдельных факторов свертывания крови и мониторинга эффективности и безопасности проводимой при этих коагулопатиях гемостатической терапии.

\section{Материалы и методы}

Работа состояла из двух этапов. Задачей первого этапа была разработка алгоритма определения дефицита отдельных факторов свертывания крови с помощью РОТЭМ. Задача второго этапа - показать на клинических примерах, как с помощью РОТЭМ можно диагностировать дефицит отдельных факторов свертывания крови и мониторировать эффективность и безопасность гемостатической терапии при этих коагулопатиях.

В исследование было включено 9 больных (4 мужчин и 5 женщин) в возрасте от 15 до 54 лет с врожденным дефицитом различных факторов свертывания крови (FV, FVII, FVIII, FIX, FXI и FXII). У 8 больных плазменная активность дефицитного фактора не превышала 1 \%, у 1 больной плазменная активность FV составила $1,7 \%$.

Для исследований гемостаза кровь у больных получали путем венепункции одной из периферических вен и собирали в пробирки S-Monovette с 3,2 \% раствором цитрата натрия в соотношении 1 часть раствора цитрата натрия, 9 частей крови. Для выполнения тестов на РОТЭМ использовали цельную цитратную кровь. Для выполнения коагуляционных тестов получали бедную тромбоцитами плазму. Бедную тромбоцитами плазму приготовляли путем центрифугирования цитратной крови со скоростью $1200 \mathrm{~g}$ (3000 об./мин) в течение 15 мин при температуре $15-25^{\circ} \mathrm{C}$. АЧТВ 
определяли в условиях стандартной активации каолином и фосфолипидами. Исследование выполняли на автоматическом коагулометре Sysmex CA-600 фирмы Sysmex Corporation (Япония) с использованием Pathromtin* SL фирмы Siemens Healthcare (Германия) [22].

Протромбиновое время (ПВ) определяли с тромбопластином, стандартизованным по международному индексу чувствительности (МИЧ 1,1) с расчетным показателем, выраженным в \%, рассчитывали международное нормализованное отношение (МНО). Исследование выполняли на автоматическом коагулометре Sysmex CA-600 фирмы Sysmex Corporation (Япония) с использованием реагента ThromoborelR S фирмы Siemens Healthcare (Германия).

Концентрацию фибриногена в плазме определяли по Клауссу. Исследование выполняли на автоматическом коагулометре Sysmex CA-600 фирмы Sysmex Corporation (Япония) с использованием реагента DadeR Thrombin Reagent фирмы Siemens Healthcare (Германия).

Определение активности факторов свертывания крови выполняли на автоматическом коагулометре Sysmex CA-600 фирмы Sysmex Corporation (Япония) одностадийным клоттинговым методом с использованием субстратных (дефицитных) образцов плазмы, лишенных одного из факторов свертывания крови. Исследование выполняли с использованием реагентов
Coagulation Factors Deficient Plasma фирмы Siemens Healthcare (Германия).

Тромбоэластометрию выполняли на 4-канальном анализаторе ROTEM delta фирмы Pentapharm $\mathrm{GmbH}$ (Германия). В исследовании были использованы пять основных тестов: EXTEM (внешний путь свертывания), INTEM (внутренний путь свертывания), FIBTEM (контроль полимеризации фибрина), HЕРТЕМ (мониторинг гепарина). Тесты выполняли согласно рекомендациям производителя. При проведении анализа использовали автоматическое пипетирование цельной цитратной крови в комбинации с различными специфическими реагентами. При постановке тестов для исследования использовали образцы стандартной плазмы (Standard human plasma, FII 100 \%, FV 90 \%, FVII 90 \%, FVIII 85-93 \%, FIX 94 \%, FX 101 \%, FXI 90 \%, FXII 97 \%, FXIII $121 \%$, Siemens Healthcare Diagnostic Products GmbH, Германия) и дефицитной по одному из факторов свертывания плазмы (Coagulation Factor Deficient Plasma, Siemens Healthcare Diagnostic Products GmbH, Германия).

\section{Результаты}

Поскольку РОТЭМ позволяет выявить нарушения как внутреннего, так и внешнего пути свертывания с помощью соответствующих тестов INTEM и EXTEM, они были использованы как скрининговые тесты для выявления коагулопатии (рис. 1).

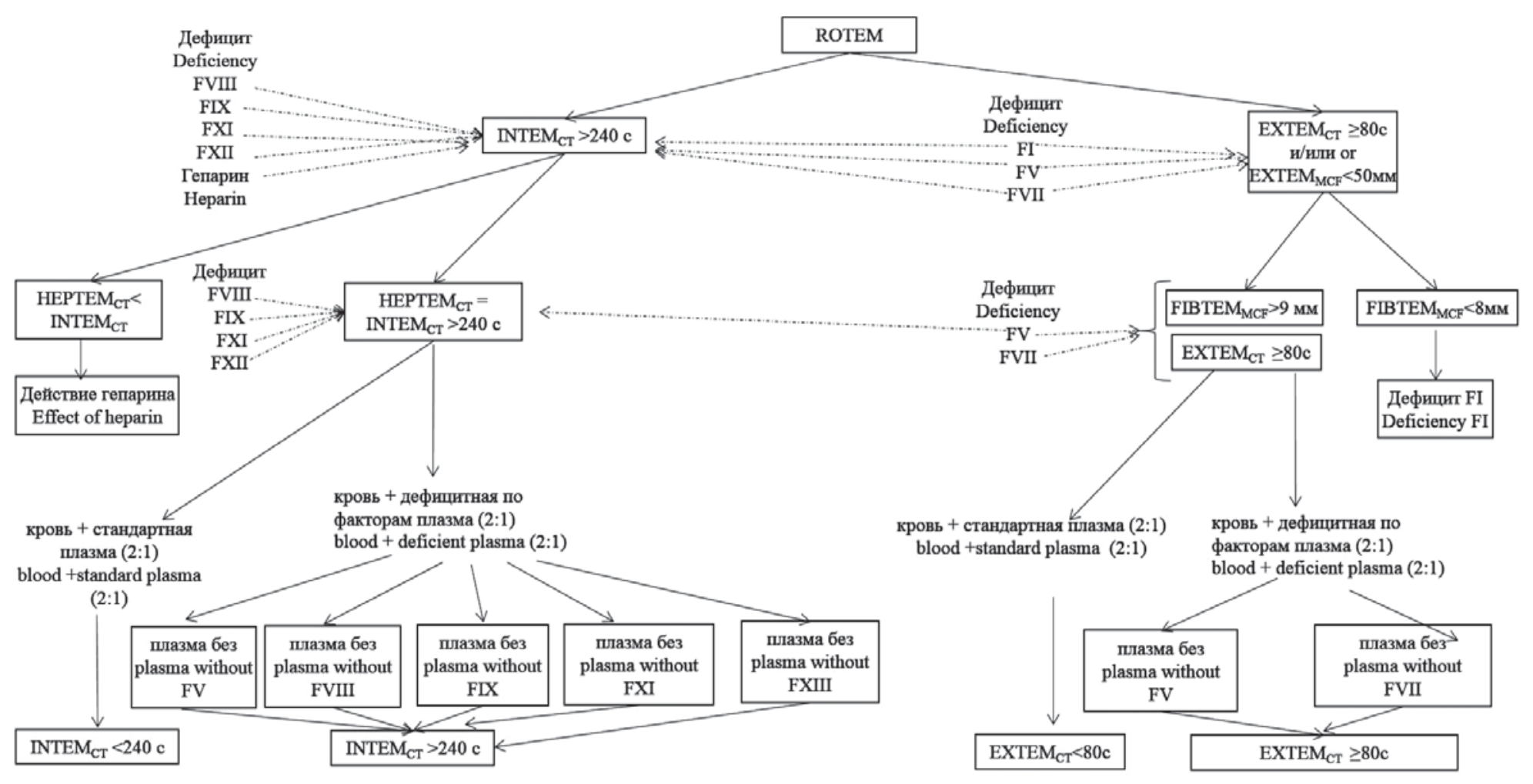

При дефиците фактора у пациента сохранится INTEM $_{\mathrm{CT}} \geq 240$ с с соответствующей дефицитной плазмой и нормализация со стандартной плазмой

При дефишите фактора у папиента сохранится ЕХТЕМ $\mathrm{ET}_{\mathrm{CT}} \geq 80 \mathrm{c}$ с соответствуюшей дефнцитной плазмой и нормализацня со стандартной плазмой

Рисунок 1. Алгоритм диагностики дефицитов факторов свертывания крови на основе РОТЭМ Figure 1. Diagnostic algorithm of coagulation factor deficiencies based on ROTEM 
В зависимости от выявленной гипокоагуляции в INTEM или EXTEM выполнялись тесты HЕРТЕМ и/или FIBTEM для исключения таких причин гипокоагуляции, как гипофибриногенемия и/или наличие гепарина в образце крови. Значения теста FIBTEM $M_{M C F}$

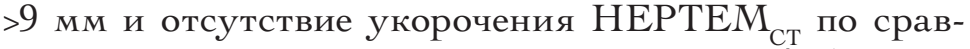
нению INTEM ${ }_{\text {CT }}$ позволяли исключить гипофибриногенемию и действие гепарина как причины гипокоагуляции. Дальнейшие исследования были направлены на выявление дефицита отдельных факторов свертывания крови (рис. 1).

Принцип выявления дефицита отдельных факторов свертывания с помощью РОТЭМ был одинаков для каждого фактора. При выявлении удлинения в тестах внешнего пути (ЕХTЕМ) и/или внутреннего пути свертывания (INTEM), исследуемую цитратную кровь смешивали в соотношении 2:1 со стандартной плазмой, в которой активность всех факторов свертывания была в норме, и с дефицитной по одному из исследуемых факторов плазмой (рис. 2).

После чего повторяли тесты ЕXTEM и/или INTEM в зависимости от участия исследуемого фактора в каскаде свертывания. При наличии дефицита одного из факторов свертывания в тесте, выполненном со смесью цельной крови и стандартной плазмой, параметр СТ укорачивался в тесте ЕXTEM и/или INTEM, а в пробе со смесью цельной крови и плазмой, дефицитной по исследуемому фактору, интервал СТ сохранялся удлиненным либо даже увеличивался еще больше вследствие дилюции.

\section{Удлинение только ЕХТЕ $M_{\text {СТ }}$ выявляется при дефищите FVII}

Для подтверждения дефищита FVII на одном канале тромбоэластометра выполняли тест EXTEM из пробирки, содержавшей смесь двух частей цельной цитратной исследуемой крови и одной части стандартной плазмы, а на другом канале выполняли тест EXTEM из пробирки, содержавшей смесь двух частей цельной цитратной исследуемой крови и одной части плазмы, дефицитной по FVII. При дефиците FVII в тесте, выполненном со смесью крови с дефицитной плазмой, сохранялось удлинение EXTEM ${ }_{\mathrm{CT}}$, а в тесте со смесью крови со стандартной плазмой происходила нормализация $\mathrm{EXTEM}_{\mathrm{CT}}$.

Одновременное удлинение ЕXTEM ${ }_{C T}$ и INTEM $M_{C T}$ выявляется при тянелом дефищите FV

Для определения дефищита $F V$ на двух каналах РОТЭМ выполняли тесты EXTEM и INTEM из пробирки, содержавшей смесь двух частей цельной цитратной исследуемой крови и одной части стандартной плазмы, а на других двух каналах — тесты EXTEM и INTEM из пробирки, содержавшей смесь двух частей цельной цитратной исследуемой крови и одной части плазмы, дефицитной по FV. При дефиците FV в тестах EXTEM и INTEM, выполненных со смесью крови с дефицитной плазмой, сохранялось удлинение $\mathrm{EXTEM}_{\mathrm{CT}}$ и INTEM ${ }_{\text {СТ }}$, а в тестах EXTEM и INTEM, выполненных со смесью исследуемой крови со стандартной плазмой, происходила нормализация EXTEM ${ }_{\mathrm{CT}}$ и INTEM $_{\mathrm{CT}}$.

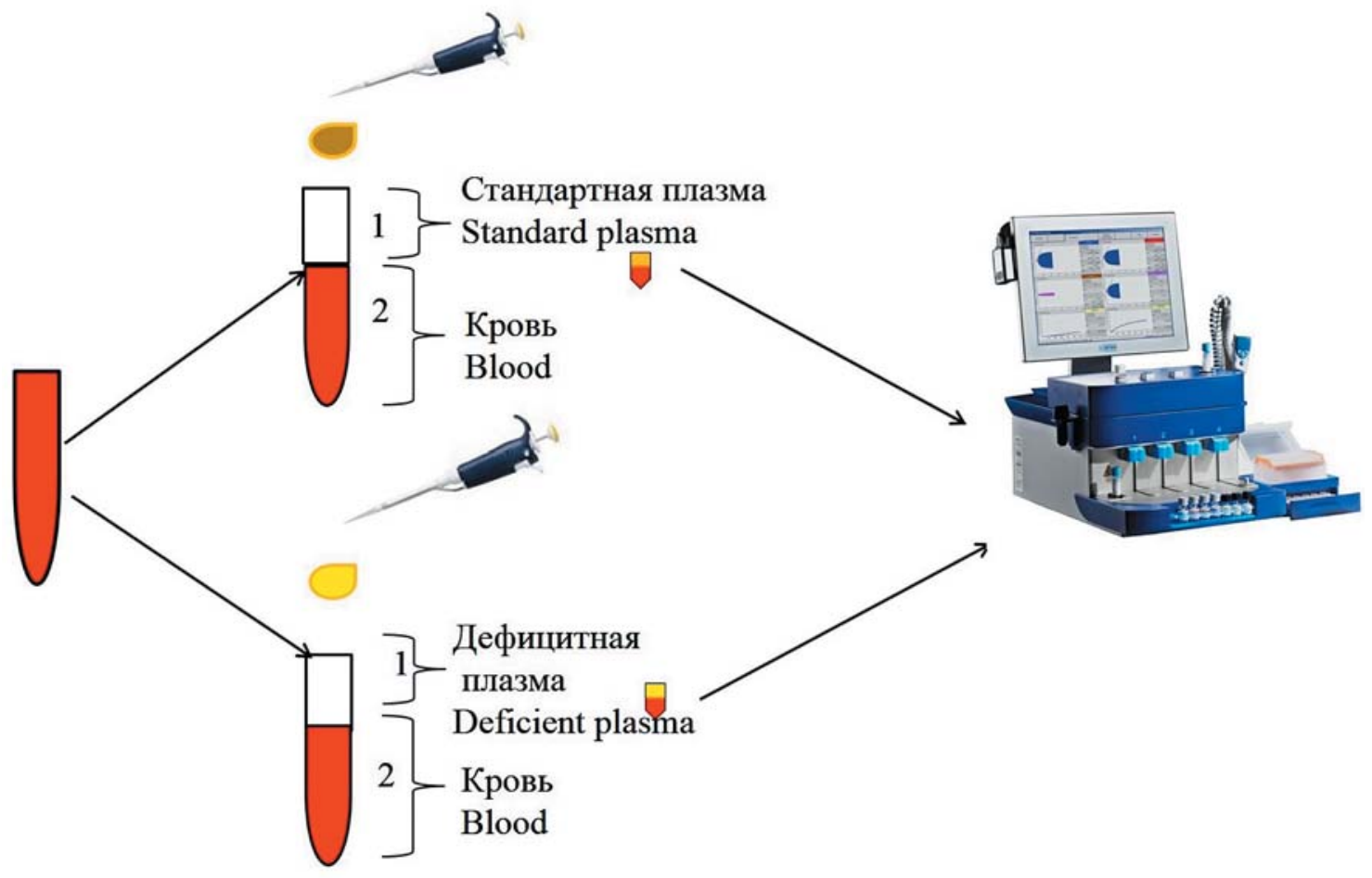

Рисунок 2. Схема выполнения исследования Figure 2. Scheme of the blood dilution 


\section{Удлинение только INTEM при дефищите FVIII, FIX, FXI и FXII}

Для выявления дефищита FVIII на одном канале РОТЭМ выполняли тест INTEM из пробирки, содержавшей смесь двух частей цельной цитратной исследуемой крови и одной части стандартной плазмы, а на другом канале выполняли тест INTEM из пробирки, содержавшей смесь двух частей цельной цитратной исследуемой крови и одной части плазмы, дефицитной по FVIII. При дефиците FVIII в тесте INTEM, выполненном со смесью крови с дефицитной плазмой, сохра-

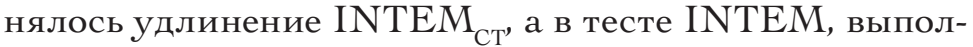
ненном со смесью исследуемой крови со стандартной плазмой, происходила нормализация INTEM ${ }_{\text {CT }}$

Для выявления дефищита FIX на одном канале РОТЭМ выполняли тест INTEM из пробирки, содержавшей смесь двух частей цельной цитратной исследуемой крови и одной части стандартной плазмы, а на другом канале выполняли тест INTEM из пробирки, содержавшей смесь двух частей цельной цитратной исследуемой крови и одной части плазмы, дефицитной по FIX. При дефиците FIX в тесте INTEM, выполненном со смесью крови с дефицитной плазмой, сохраня-

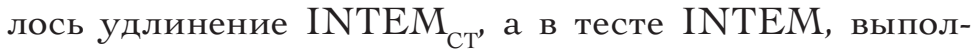
ненном со смесью исследуемой крови со стандартной плазмой, происходила нормализация INTEM $\mathrm{CT}$.

Для выявления дефищита FXI на одном канале РОТЭМ выполняли тест INTEM из пробирки, содержавшей смесь двух частей цельной цитратной исследуемой крови и одной части стандартной плазмы, а на другом канале выполняли тест INTEM из пробирки, содержавшей смесь двух частей цельной цитратной исследуемой крови и одной части плазмы, дефицитной по FXI. При дефиците FXI в тесте INTEM, выполненном со смесью крови с дефицитной плазмой, сохраня-

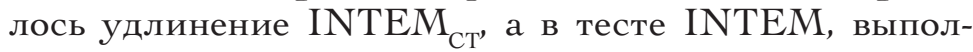
ненном со смесью исследуемой крови со стандартной плазмой, происходила нормализация INTEM

Для выявления дефищита FXII выполняли на одном канале РОТЭМ выполняли тест INTEM из пробирки, содержавшей смесь двух частей цельной цитратной исследуемой крови и одной части стандартной плазмы, а на другом канале выполняли тест INTEM из пробирки, содержавшей смесь двух частей цельной цитратной исследуемой крови и одной части плазмы, дефицитной по FXII. В тесте INTEM, выполненном со смесью крови с дефицитной плазмой, сохранялось удлинение

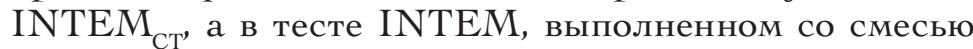
исследуемой крови со стандартной плазмой, происходила нормализация INTEM ${ }_{\text {CT. }}$

Ниже приведены примеры диагностики дефицита факторов у больных врожденными коагулопатиями.

\section{Диагностика дефищита FVII}

Больной О., 28 лет, страдает гипопроконвертинемией. Заболевание протекает с геморрагическим синдромом в виде желудочно-кишечных и носовых кровотечений. Основные показатели системы гемостаза: АЧТВ 31 с, протромбин по Квику 14,5 \%, MНО 4,6, фибриноген 2,3 г/л, плазменная активность FVII 1,7 \%. В тесте INTEM не выявлено отклонений от нормы, в тесте ЕХТЕМ выявлено удлинение ЕХTЕМ (норма до 79 с), в тесте FIBTEM показатель MCF был в пределах нормы (12 мм), что исключило гипофибриногенемию как причину гипокоагуляции (рис. 3).
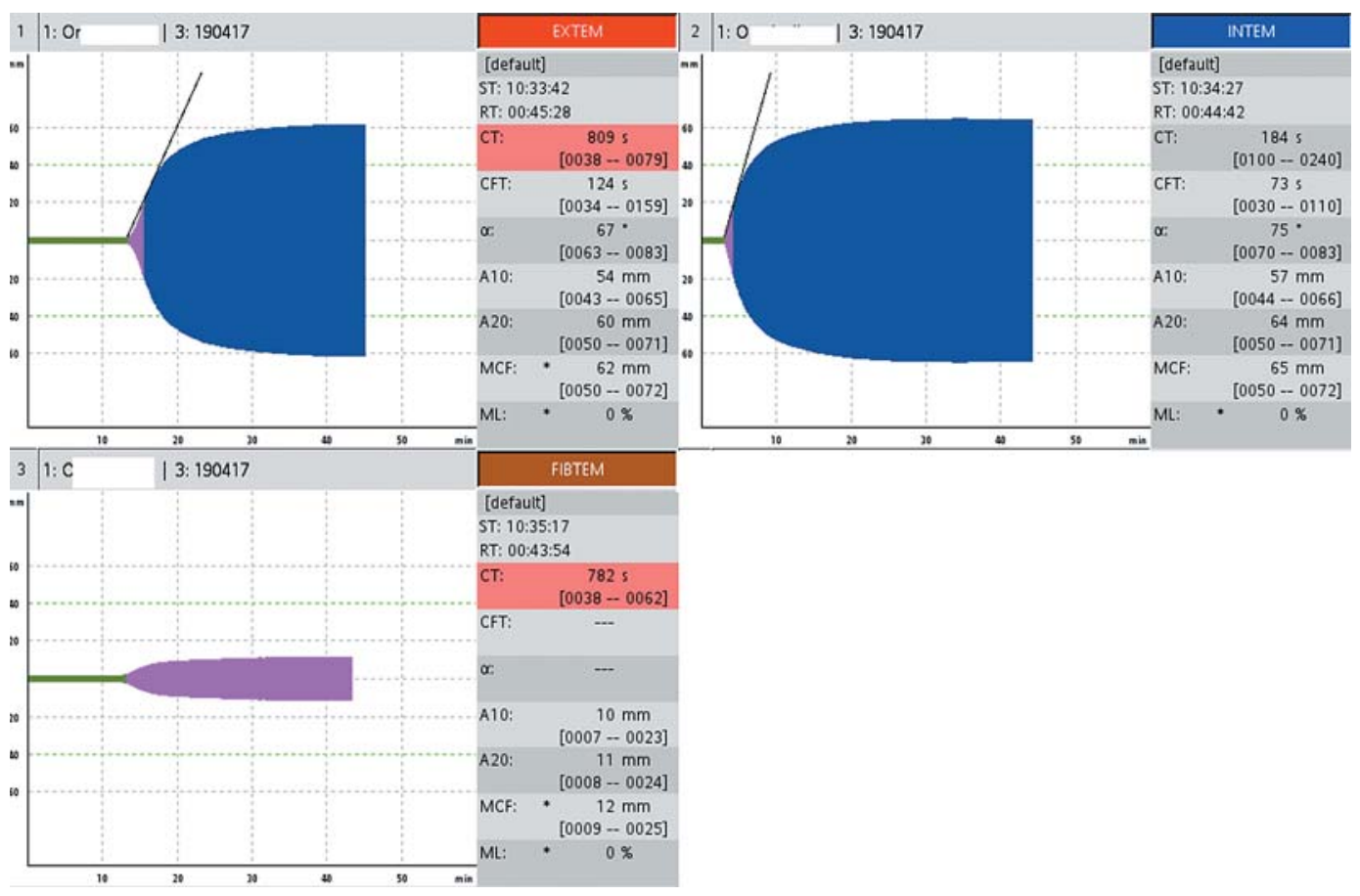

Рисунок 3. Показатели РОТЭМ больного гипопроконвертинемией: удлинение EXTEM C' нормальные INTEM FIBTEM $_{\text {MCF }}$ Figure 3. ROTEM patterns of patient with hypoproconvertinemia, prolonged EXTEM $M_{C T^{\prime}}$ normal INTEM CT and FIBTEM ${ }_{M C F}$ 
В тесте ЕХТЕМ, выполненном со смесью цельной цитратной крови со стандартной плазмой, $\mathrm{EXTEM}_{\mathrm{CT}}$ сократился до 75 с, а в тесте EXTEM, выполненном со смесью цельной цитратной крови с плазмой, дефицитной по FVII, EXTEM ным до 490 с, что свидетельствует об изолированном дефиците FVII. На рисунке 4 представлен тест EXTЕМ при постановке со смесью цельной крови больного с дефицитом FVII со стандартной плазмой и смесью цельной крови больного с дефицитом FVII и плазмой, дефицитной по FVII. Происходит нормализация СТ в смеси со стандартной плазмой и сохраняется гипокоагуляция в смеси с дефицитной плазмой (рис. 4).

\section{Оченка эффективности гемостатической} терапии у больной гипопроконвертинемией

Больной 3., 27 лет, страдающей гипопроконвертинемией, выполнено лапароскопическое удаление кисты яичника. До и после оперативного вмешательства выполнялись коагулогические исследования, измерялась плазменная активность FVII, выполнялась тромбоэластометрия. Как видно из таблицы 1 , до введения рекомбинантного активированного фактора свертывания VII (rFVIIa) отмечалось выраженное удлинение EXTEM до 405 с. После введения rFVIIа у больной уменьшился $\mathrm{EXTEM}_{\mathrm{CT}}$ с 405 до 71 с, т.е. до нормы, и лишь через 12 ч возникли показания к повторному введению rFVIIa

Таблица 1. Мониторинг гемостатической терапии rFVlla у больной с гипопроконвертинемией

Table 1. Monitoring of rFVIla hemostatic treatment of patient with hypoproconvertinemia

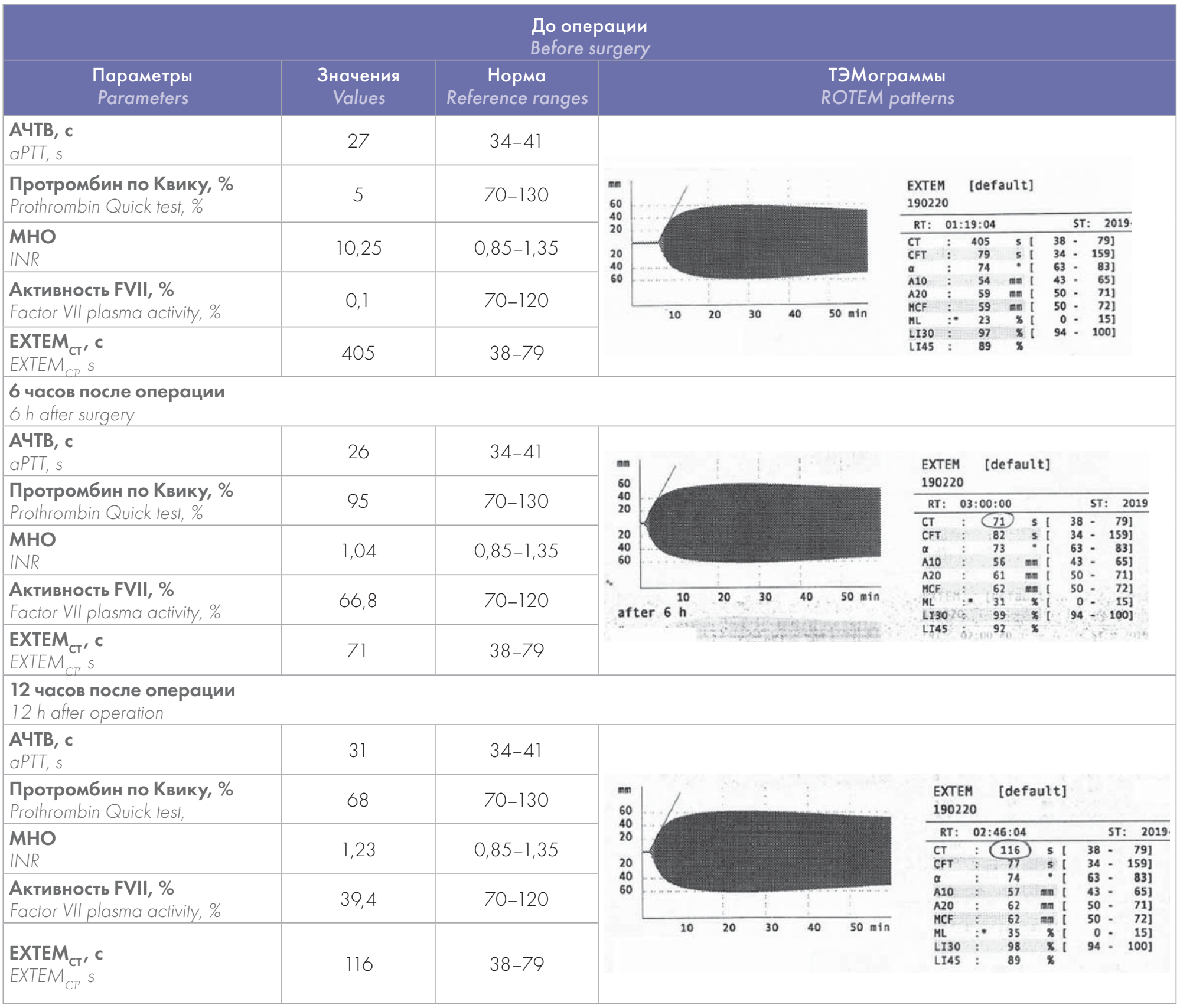




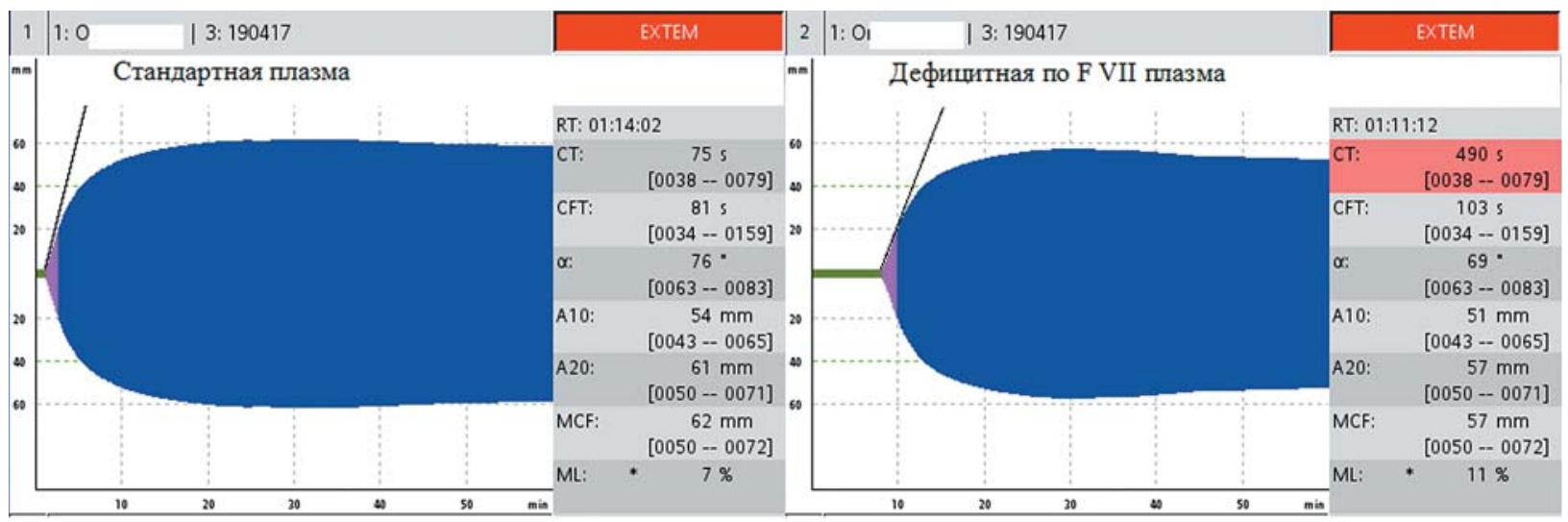

Рисунок 4. Изменения CT в EXTEM в смеси крови больного гипопроконвертинемией со стандартной плазмой (нормализация СT) и плазмой, дефицитной по FVII (сохраняется удлинение СТ)

Figure 4. Changes of EXTEM in the mixture of patient's blood with standard plasma (CT normalization) and with coagulation factor deficient plasma in hypoproconvertinemia

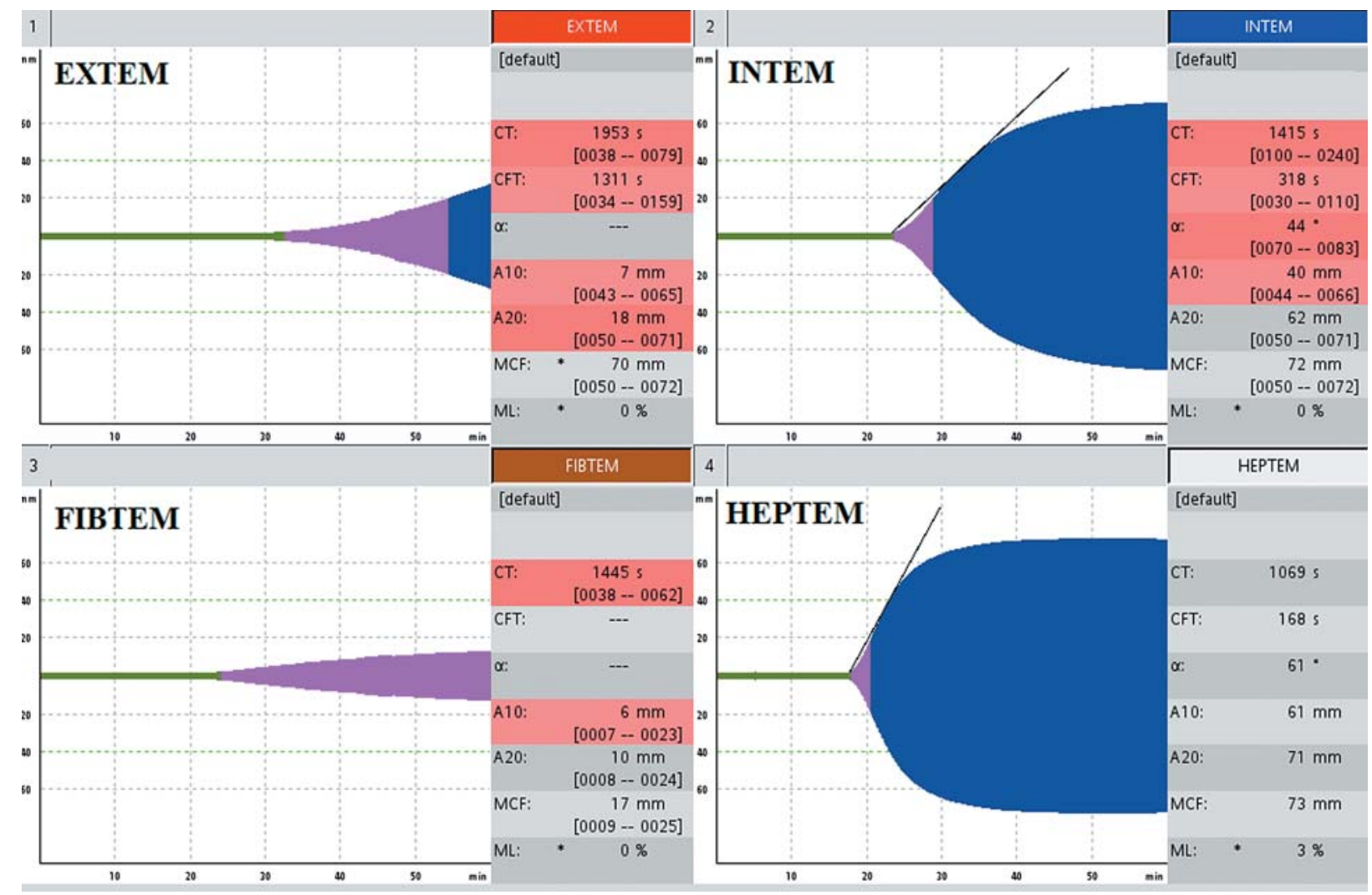

Рисунок 5. РОТЭМ у больной с дефицитом FV: удлинение EXTEM и и INTEM ст, нормальный FIBTEM Figure 5. ROTEM patterns of patient with factor $V$ deficiency: prolonged EXTEM ${ }_{C T}$ and INTEM $M_{C T}$ normal FIBTEM $M_{M C M^{\prime}}$ the lack of CT normalization in HEPTEM test

(удлинение EXTEM в плазме была при этом $39 \%$, а МНО 1,23.

Таким образом, использование РОТЭМ позволило контролировать гемостаз во время операции и в послеоперационном периоде и принять решение о повторном введении rFVIIa.

\section{Диагностика дефищита FV}

Больная Д., 18 лет, врожденный дефицит FV у нее был выявлен в возрасте 7 лет. Геморрагический синдром проявляется маточными кровотечениями, гематомами различной локализации (плазменная активность FV 0,5 \%, АЧТВ 200 с, протромбин по Квику 10,7 \%). В тесте ЕХTЕМ выявлено удлинение СТ до 1953 с (норма до 79 с), в тесте INTEM - удлинение СТ до 1415 с (норма до 240 с). Показатель FIBTEM 17 мм позволил исключить дефицит фибриногена. Сохраняющееся удлинение СТ до 1069 с в тесте НЕРТЕМ позволило исключить действие гепарина как причины гипокоагуляции (рис. 5).

При выполнении тестов со смесью цельной цитратной крови со стандартной плазмой интервал EXTEM $_{\text {Ст }}$ укоротился до 79 с, INTEM зовались. При выполнении тестов со смесью цельной цитратной крови с плазмой, дефицитной по FV, сохранилось патологическое удлинение EXTEM $_{\text {Ст }}$ до 475 с и INTEM $\mathrm{CT}_{\text {до }} 1060$ с, что подтвердило дефицит FV (рис. 6). 

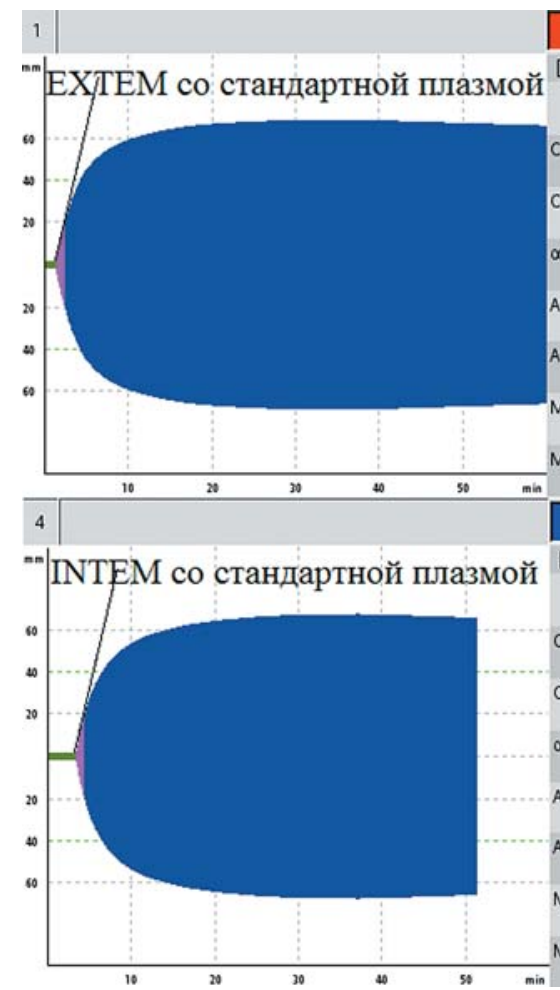
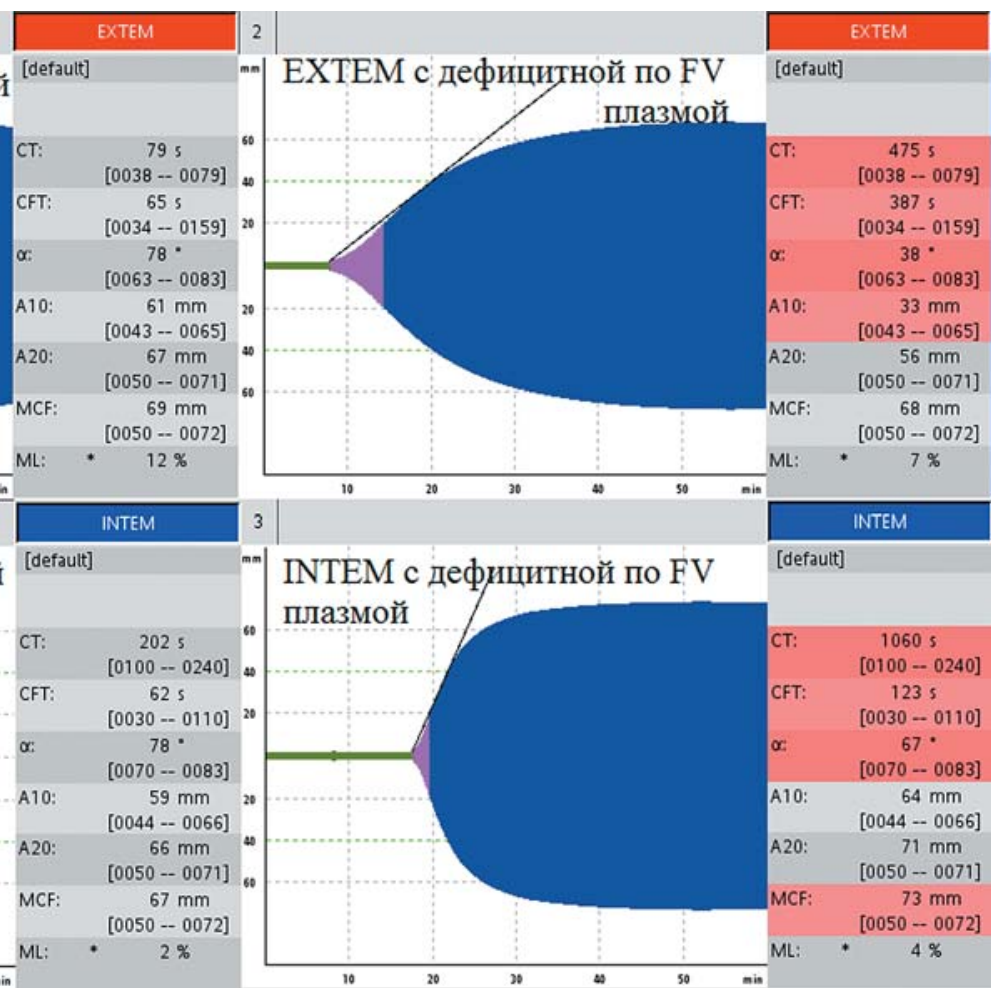

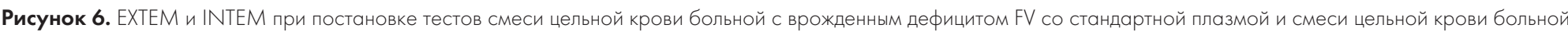

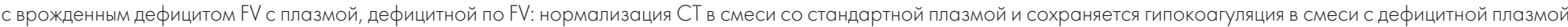

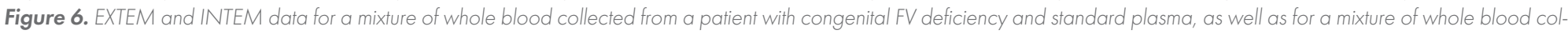

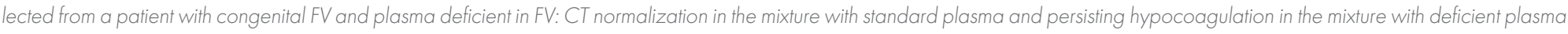

\section{Оценка эффективности гемостатической терапии у больной с дефищитом $F V$}

Больной И., 21 года, с врожденным дефицитом FV (плазменная активность FV 0,5 \%) была выполнена имплантация венозной порт-системы. Коррекция гипокоагуляции проводилась трансфузией свежезамороженной плазмы (СЗП) и концентратом тромбоцитов. В таблице 2 представлены основные коагулогические показатели и результаты тромбоэластометрии до и после заместительных трансфузий. Особенностью данного клинического примера являлось то, что у больной в анамнезе были эпизоды венозных тромбозов после лечения СЗП. Поэтому основной задачей лечения было компенсировать гипокоагуляцию таким образом, чтобы избежать гиперкоагуляции. До операции отмечалось выраженное удлинение EXTEM до 79 с). После трансфузии СЗП и концентрата тромбоцитов у больной уменьшился EXTEM ность FV в плазме стала 19,5 \%, MНО - 1,58 (табл. 2). Установлена порт-система без осложнений.

\section{Пример 5. Диагностика дефищита FVIII}

Больному А., 32 лет, диагноз гемофилия А был установлен в детском возрасте. В анамнезе отмечались рецидивирующие гемартрозы, кровотечения после экстракции зубов. Плазменная активность FVIII составляла 0,7-1,5 \%. При настоящем обследовании в результате профилактической гемостатической терапии концентратом FVIII: АЧТВ 57 с, протромбин по Квику 110 \%, фибриноген 2,4 г/л, активность FVIII 11 \%. При обследовании в соот- ветствии с алгоритмом диагностики дефицита факторов свертывания с помощью РОТЭМ (рис. 1) в тесте ЕХТЕМ не выявлено отклонений от нормы, в тесте INTEM выявлено удлинение СТ до 872 с (норма до 240 с) (рис. 7).

Сохранение гипокоагуляции в тесте НЕРТЕМ исключило влияние гепарина (рис. 7). При выполнении теста INTEM со стандартной плазмой и плазмой, дефицитной по FVIII, выявлено укорочение INTEM до 232 с в пробе со стандартной плазмой и сохранение удлинения INTEM дефицитной по FVIII (рис. 8), что подтвердило дефицит FVIII. Дальнейшее увеличение INTEM бе с дефицитной плазмой можно объяснить дилюцией и уменьшением концентрации FVIII.

\section{Диагностика дефищита FIX}

Больной И., 15 лет, с рождения возникали спонтанные внутримышечные гематомы, носовые кровотечения, гемартрозы обоих коленных суставов. Диагностирована гемофилия B, тяжелая форма (FIX $<1$ \%). При настоящем обследовании АЧТВ 151 с, протромбин по Квику 71 \%, фибриноген 2,9 г/л, плазменная активность FIX 0,5 \%. При обследовании в соответствии с алгоритмом диагностики дефицита факторов свертывания (рис. 1) в тесте EXTEM не выявлено отклонений от нормы, выявлено удлинение INTEM

С помощью теста НЕРТЕМ было исключено действие гепарина. При исследовании цельной крови со стандартной плазмой INTEM $\mathrm{CT}_{\text {T }}-185$ с, в тесте с дефицитной плазмой INTEM $\mathrm{CT}_{\mathrm{C}}-485$ с (рис. 10), что подтвердило диагноз гемофилии В. 
Таблица 2. Изменения показателей после гемостатической терапии СЗП и концентратом тромбоцитов у больной с дефицитом FV Table 2. Changes of coagulation parameters of patient with factor $V$ deficiency after hemostatic treatment with fresh frozen plasma and platelet concentrate

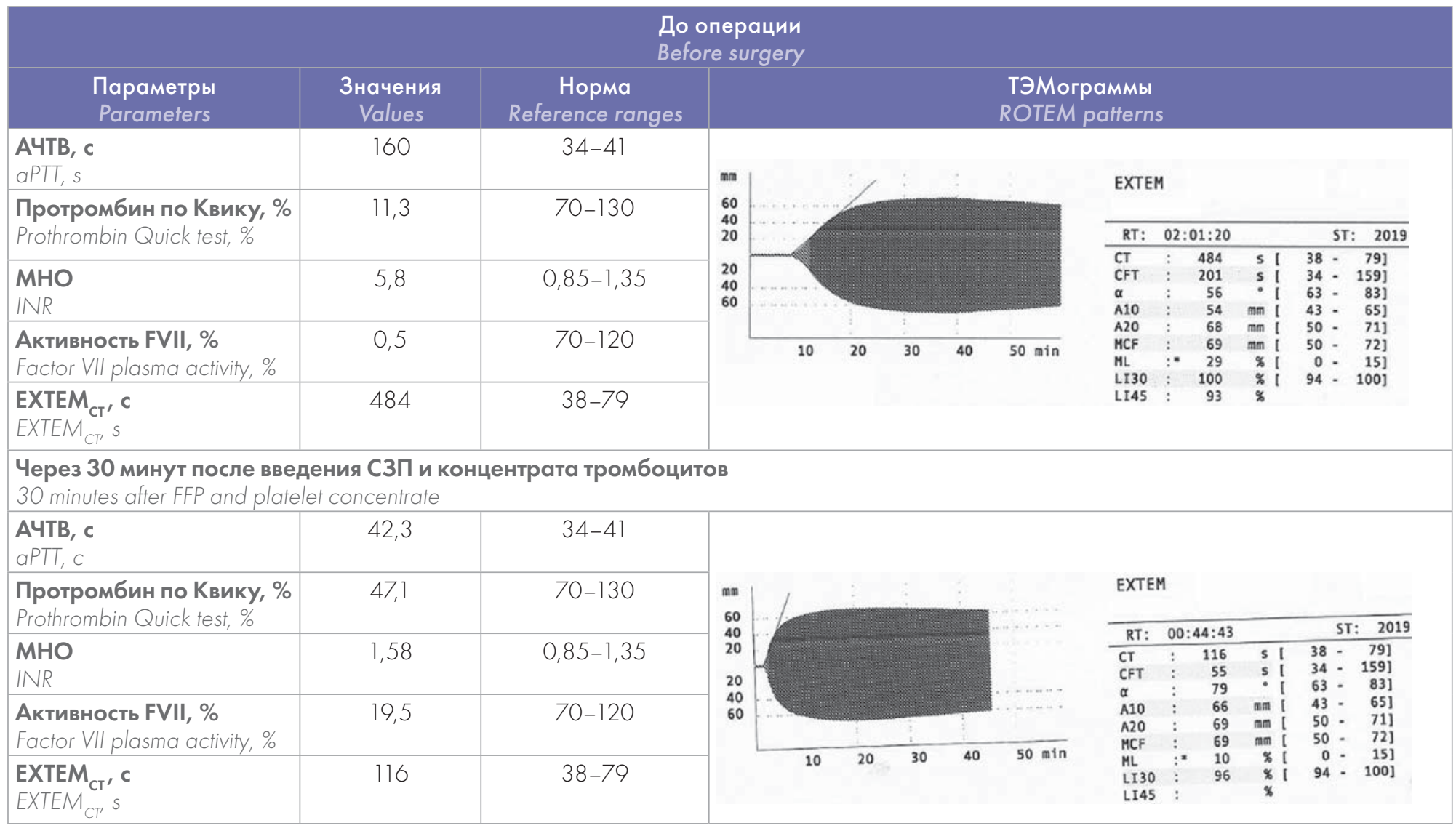

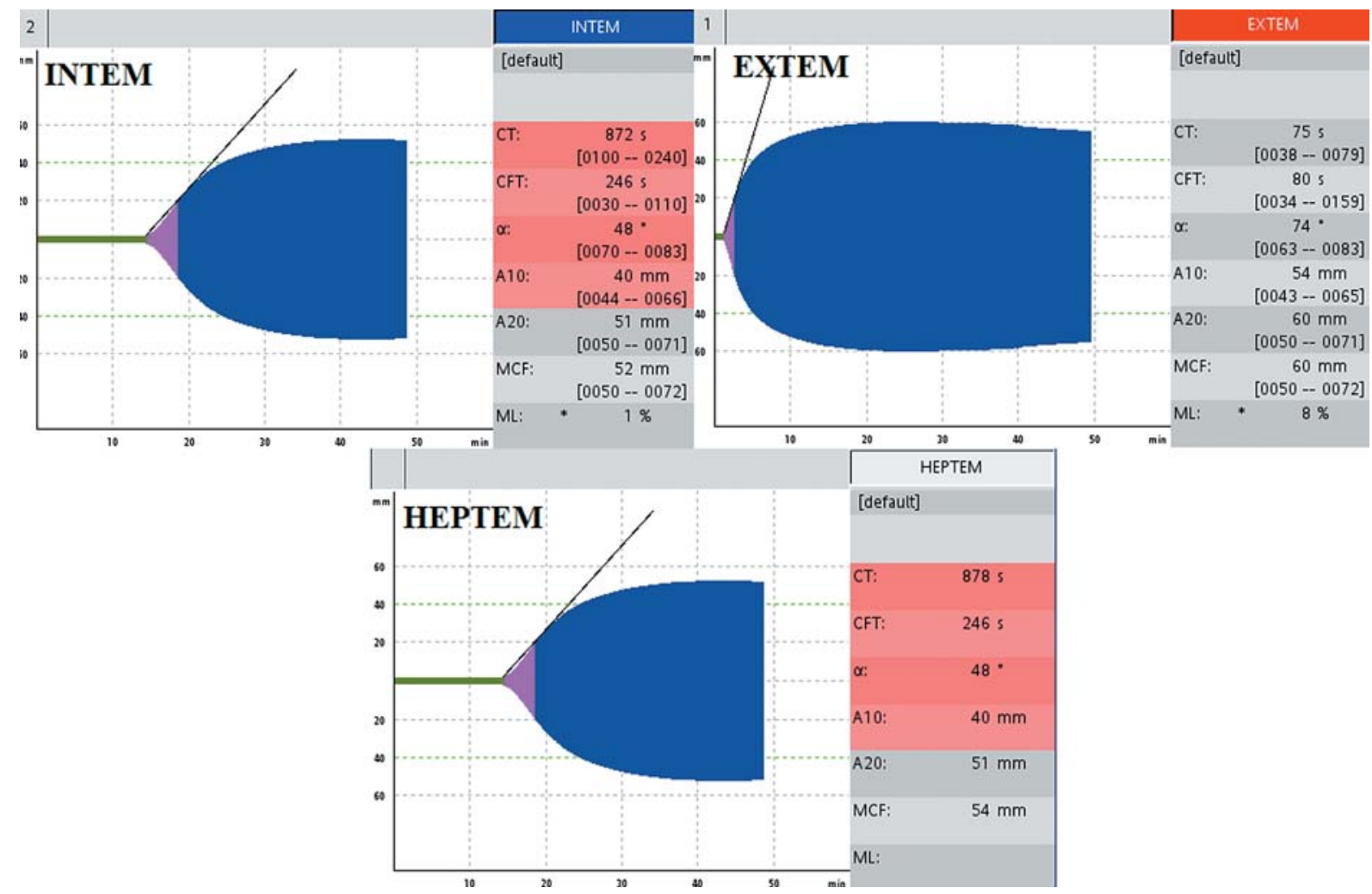

Рисунок 7. Показатели РОТЭМ больного гемофилией А: удлинение INTEM Figure 7. ROTEM in patient with hemophilia A: prolonged INTEM ${ }_{C T}$ normal EXTEM ${ }_{C T}$ the lack of CT normalization in HEPTEM test 


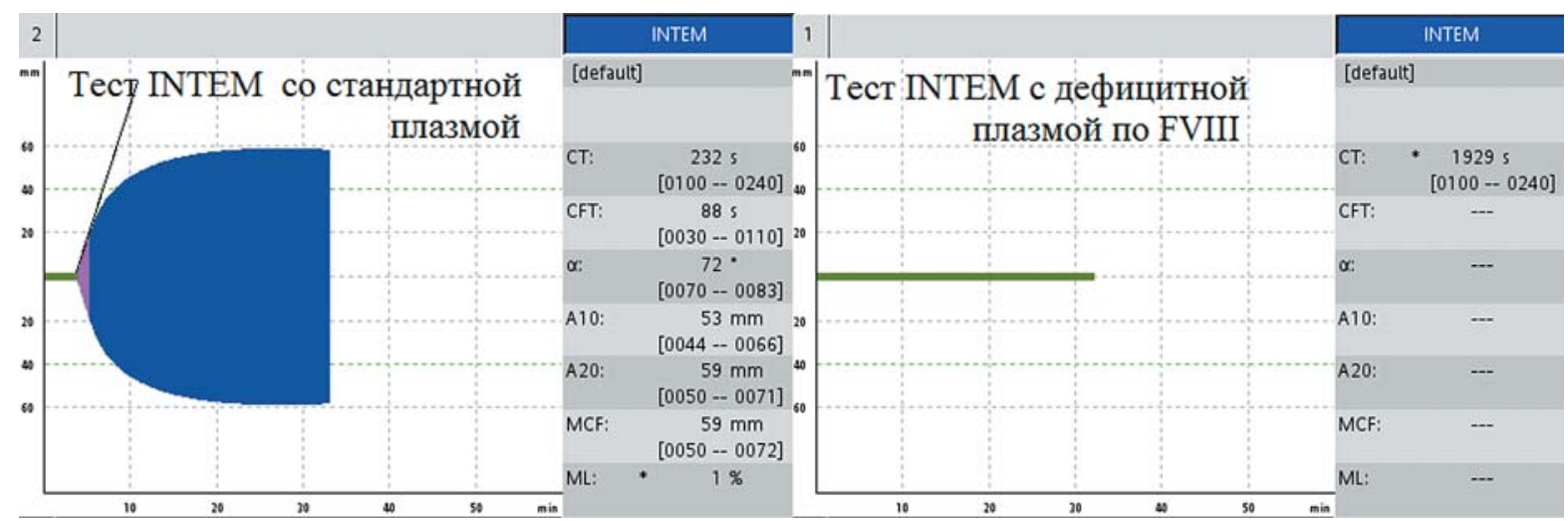

Рисунок 8. Тесты INTEM при постановке со смесью цельной крови больного гемофилией A со стандартной плазмой и смесью цельной крови больного гемофилией А и плазмой, дефицитной по FVIII: нормализация СТ в смеси со стандартной плазмой и гипокоагуляция в смеси с дефицитной плазмой

Figure 8. INTEM of patient with hemophilia A in the mixture of patient's blood with standard plasma and in the mixture of patient's blood with coagulation factor VIII deficient plasma: CT normalization in the mixture with standard plasma and hypocoagulation in the mixture with coagulation factor deficient plasma

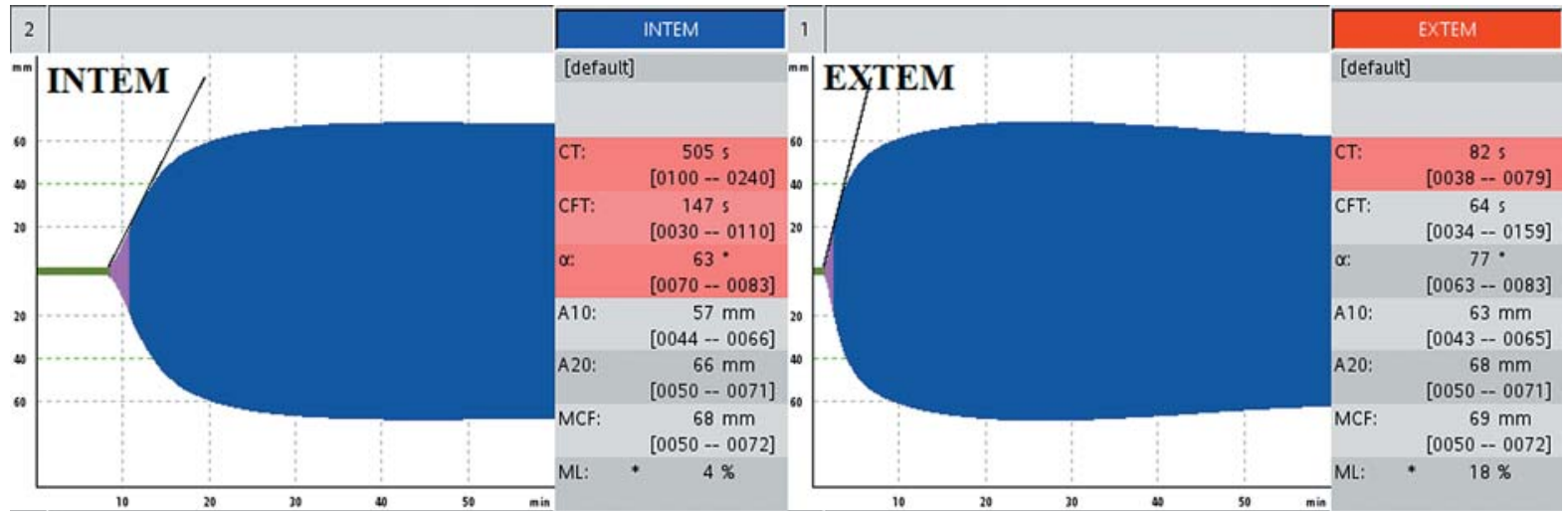

Рисунок 9. Показатели РОТЭМ у больного гемофилией В: удлинение INTEM

Figure 9. ROTEM in patient with hemophilia B: prolonged INTEM ${ }_{C T}$ normal EXTEM $C T$

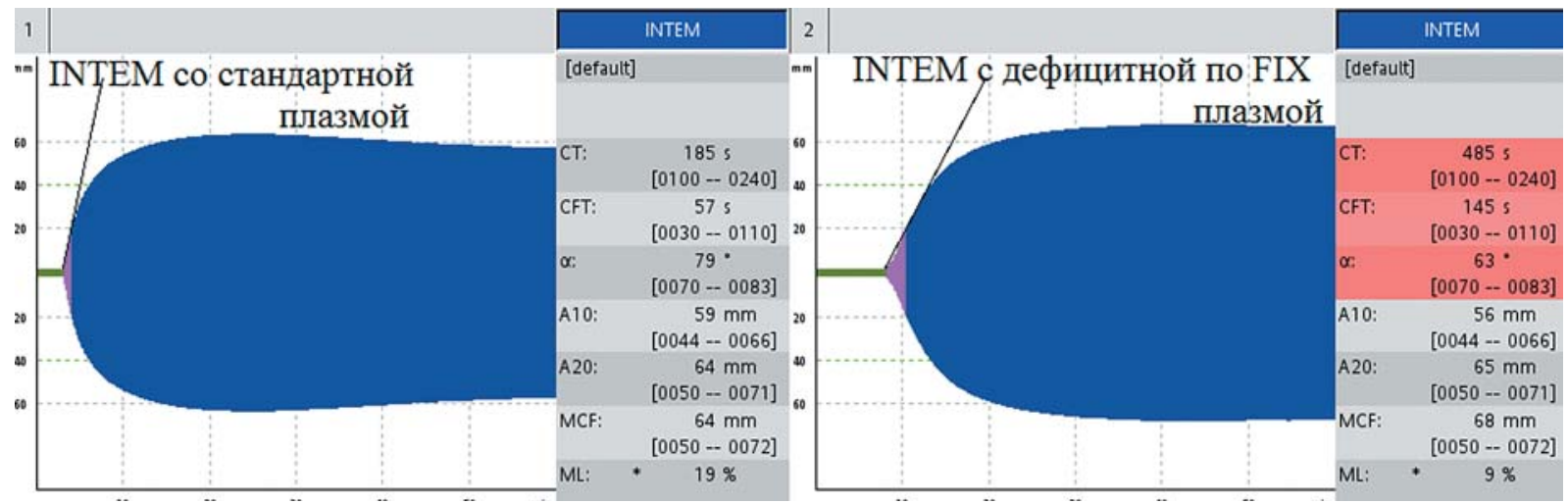

Рисунок 10. Тесты INTEM при постановке со смесью цельной крови больного гемофилией В со стандартной плазмой и смесью цельной крови больного и плазмой, дефицитной по FIX: нормализация СТ в смеси со стандартной плазмой и гипокоагуляция в смеси с дефицитной плазмой

Figure 10. INTEM of patient with hemophilia B in the mixture of patient's blood with standard plasma and in the mixture of patient's blood with coagulation FIX deficient plasma: CT normalization in the mixture with standard plasma and hypocoagulation in the mixture with coagulation factor deficient plasma

\section{Диагностика дефищита фактора свертьввания XI}

Больная К., 44 лет, страдает гемофилией С (дефицит ХІ). Жалобна спонтанную кровоточивостьнепредъявляла, считала себя здоровой. Диагноз был установлен при обследовании перед хирургическим вмешательством: АЧТВ удлинено до 90 с, протромбин по Квику $92 \%$, фибриноген 3,3 г/л, активность FXI составила $0,7 \%$. При обследовании в соответствии с алгоритмом диагностики дефицита факторов свертывания (рис. 1) в тесте ЕХTЕМ не выявлено отклонений от нормы, выявлено удлинение INTEM

С помощью теста НЕРТЕМ было исключено действие гепарина. При исследовании цельной крови больной со стандартной плазмой INTEM 203 с, в то время как в тесте с дефицитной плазмой INTEM $_{\text {CT }}-637$ с (рис. 12), что подтвердило наличие дефицита FXI как причины гипокоагуляции. 

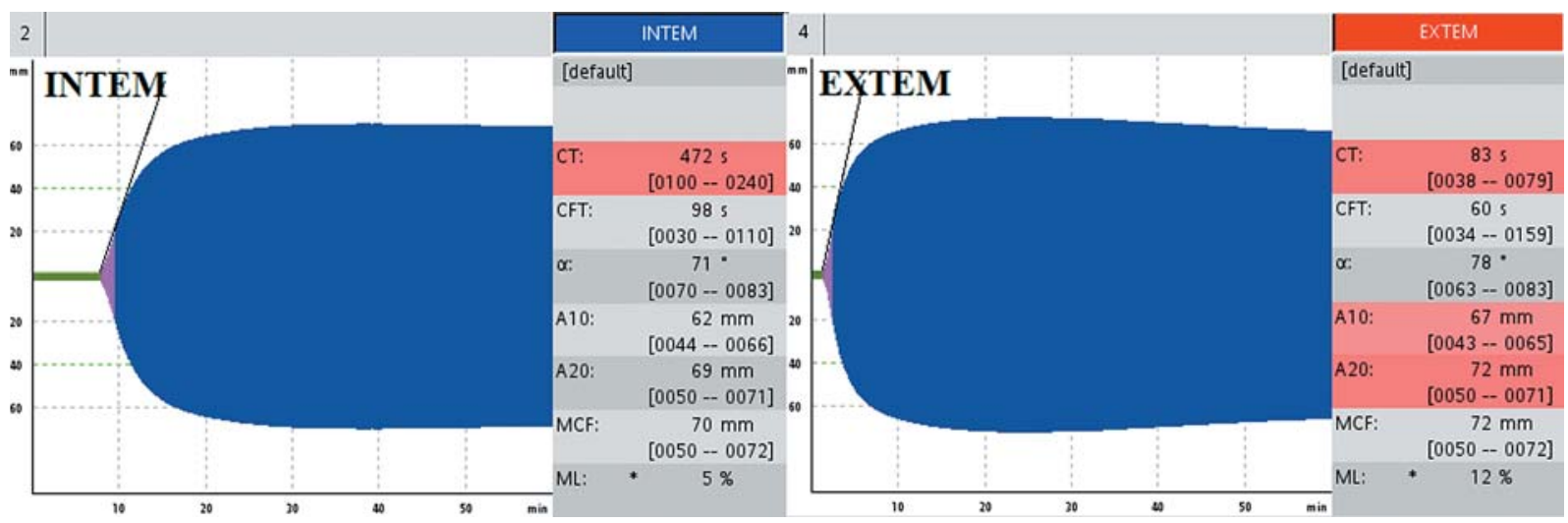

Рисунок 11. Показатели РОТЭМ у больной гемофилией С: удлинение INTEM ${ }_{\text {Ст, нормальный EXTEM }}$

Figure 11. ROTEM in patient with hemophilia C: prolonged INTEM CT' normal EXTEM CT

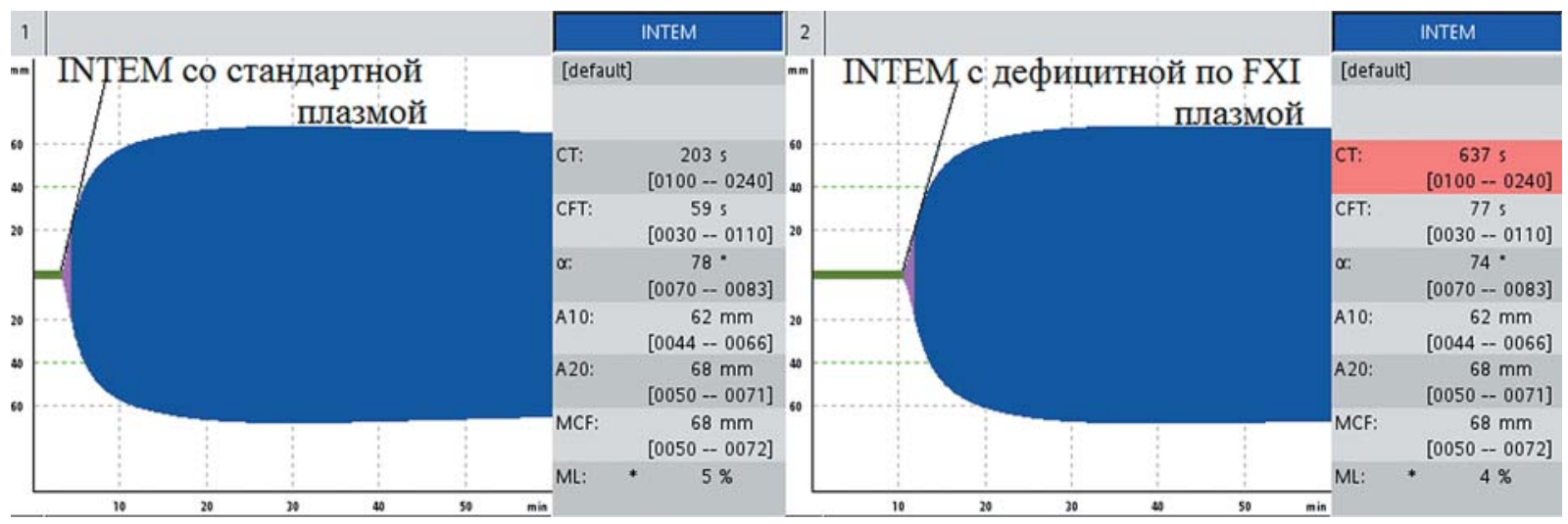

Рисунок 12. INTEM при постановке тестов со смесью цельной крови больной гемофилией $C$ со стандартной плазмой и смеси цельной крови больной гемофилией С и плазмой, дефицитной по FXI: нормализация СТ в смеси со стандартной плазмой и гипокоагуляция в смеси с дефицитной плазмой

Figure 12. INTEM of patient with hemophilia $C$ in the mixture of patient's blood with standard plasma and in the mixture of patient's blood with coagulation FXI deficient plasma: CT normalization in the mixture with standard plasma and hypocoagulation in the mixture with coagulation factor deficient plasma

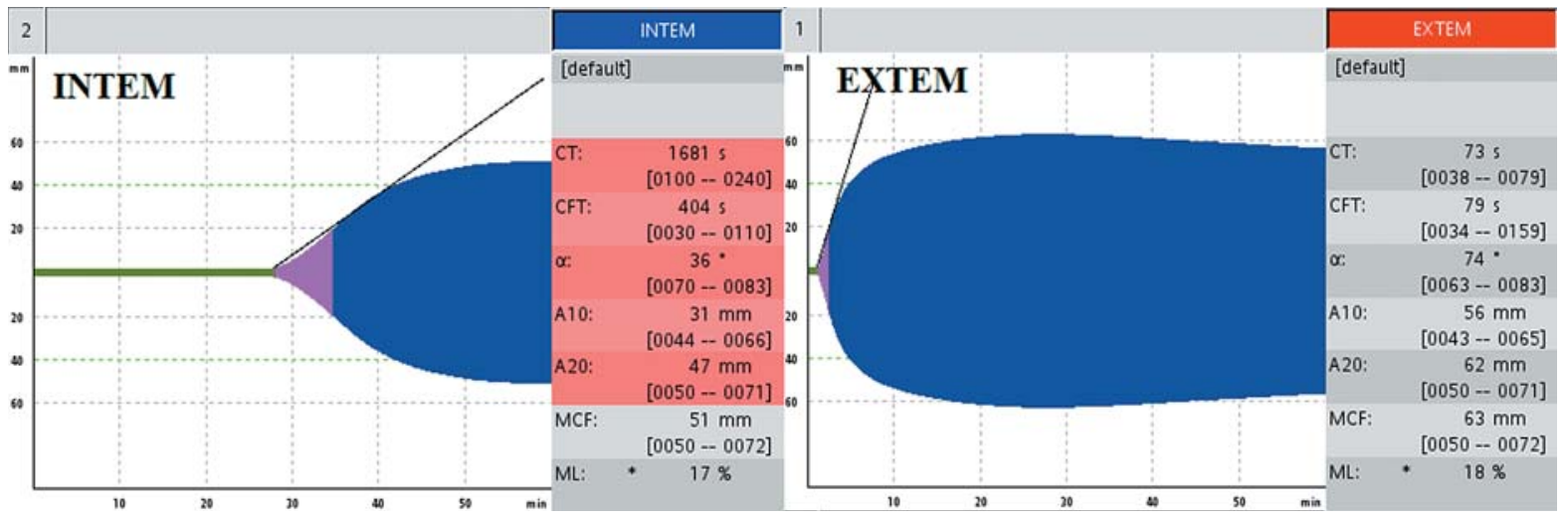

Рисунок 13. Показатели РОТЭМ у больной болезнью Хагемана (дефицит FXII) с: удлинение INTEM ст, нормальный EXTEM Figure 13. ROTEM in patient with Hageman's disease (factor XII deficiency): prolonged INTEM CT normal EXTEM CI

\section{Диагностика дефищита FXII}

Больная Д., 47 лет, страдает болезнью Хагемана (дефицит FXII). Заболевание впервые диагностировано в возрасте 37 лет, когда накануне оперативного вмешательства было выявлено удлинение АЧТВ до 86 с, активность FXII составляла менее $1 \%$. В соответствии с алгоритмом диагностики дефицита факторов свертывания (рис. 1) в тесте ЕХTЕМ не выявлено отклонений от нормы, выявлено удлинение INTEM (норма до 240 с) (рис. 13).
С помощью теста НЕРТЕМ было исключено действие гепарина. При исследовании цельной крови больной со стандартной плазмой INTEM зовался -243 с, в то время как в тесте с плазмой, дефицитной по FXII, INTEM 694 с (рис. 14), что подтвердило дефицит FXII.

Оченка эффективности гемостатической терапии у больного с врожденньмм дефищитом FXII

Больному В., 54 лет, с диагнозом болезнь Хагемана, выполнено эндопротезирование коленного сустава. 

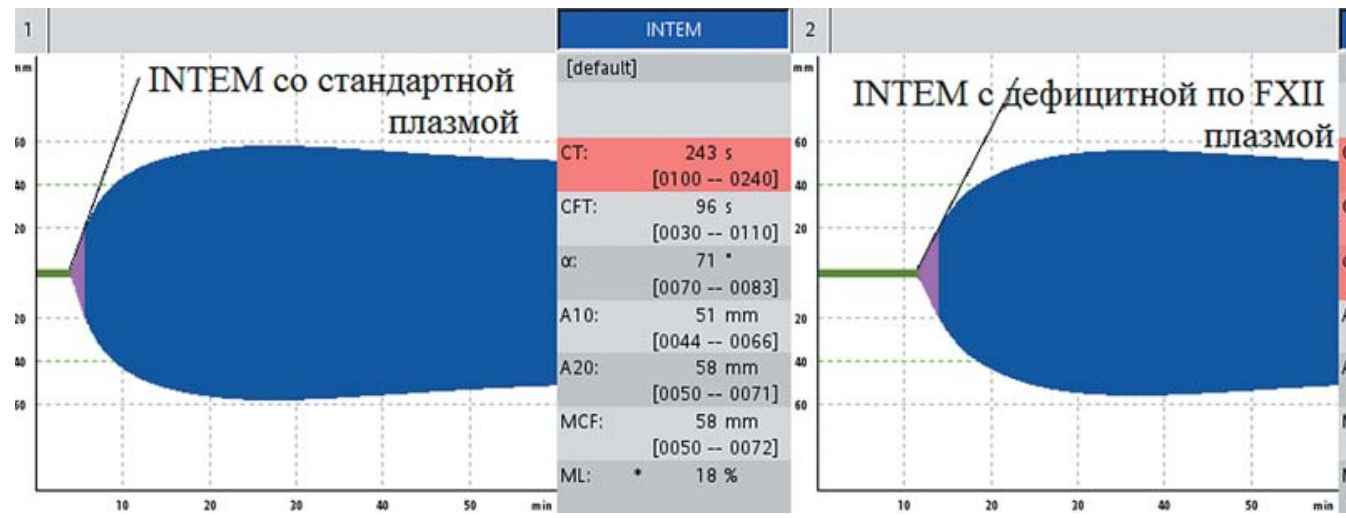

INTEM

[default]

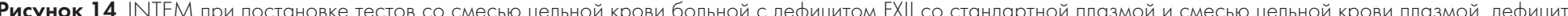
по FXII: нормализация СТ в смеси со стандартной плазмой и гипокоагуляция в смеси с дефицитной плазмой

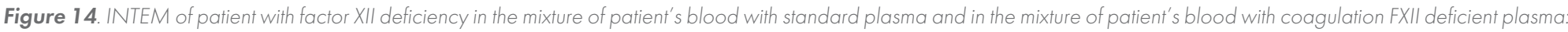
CT normalization in the mixture with standard plasma and hypocoagulation in the mixture with coagulation factor deficient plasma

До операции в коагулограмме: АЧТВ 164 с, концентрация фибриногена 3,8 г/л; протромбин по Квику 90 \%, МНО 1,06; плазменная активность FXII 1 \%. При исследовании методом РОТЭМ цельной крови удлинение INTEM СТ $_{103}$ с (рис. 15).

После трансфузии СЗП в коагулограмме АЧТВ сократилось до 45 с. При исследовании методом РОТЭМ после терапии СЗП уменьшился до нормальных значений INTEM ${ }_{\text {CT }} 193$ с (рис. 16). В послеоперационном периоде каких-либо геморрагических и тромботических осложнений не наблюдалось.

\section{Обсуждение}

К наследственным (врожденным) коагулопатиям относятся моногенные коагулопатии, которые вызваны дефицитом плазменных белков, участвующих в гемостазе [23]. Наиболее распространенным заболеванием в этой группе является гемофилия, редкие наследственные коагулопатии включают дефицит FI, FII, FV, FVII, FX, FXI, FXII. Причиной их развития является, как правило, рецессивное наследование уникального или редких нуклеотидных изменений в генах, кодирующих коагуляционные факторы, или в белках, необходимых для посттрансляционных модификаций данных факторов. Эти заболевания наиболее распространены в этнических группах, в которых приняты близкородственные браки, вследствие вероятности гомозиготного носительства дефекта гена [23]. До недавнего времени описания редких когулопатий состояли из исследований случай-контроль или малочисленных когортных исследований. Однако в последние годы появилось несколько специфических регистров. К ним можно отнести регистр Европейской сети редких геморрагических заболеваний (European Network of the Rare Bleeding Disorders) [24], североамериканский регистр [25], английский (UKHDCO, www.ukhdco. org), итальянский (http://www.aiceonline.it), швейцарский (www.aekreg.ch), бразильский и международный (htttp://www.factorxi.org) регистры [26, 27]. Инцидентность этих редких врожденных коагулопатий колеблется от 1 : 500000 до 1 : 2000000 населения [26]. Даже среди остальных врожденных коагулопатий редкие нарушения свертывания крови встречаются нечасто. По данным итальянского регистра [28], в который в 2016 г. было включено 10300 больных орфанными нарушениями свертывания крови, а именно гемофилией, болезнью Виллебранда и дефицитом отдельных факторов свертывания, больные с дефицитом отдельных факторов составляли всего 2093 человека, или $20,2 \%$.

В настоящей работе разработан алгоритм диагностики дефицита FV, FVII, FXI, FXII.

При тяжелой форме дефищита FV (болезнь Оврена) у больных обнаруживают удлинение ПВ и АЧТВ. Удлинение времени в обоих тестах связано с тем, что FV входит в состав протромбиназного комплекса общего пути свертывания, который катализирует превращение тромбина из протромбина. Диапазон нормальных значений плазменной активности FVII составляет 70 $120 \%[22,29,30]$.

При дефищите FVII, или гипопроконвертинемии, спонтанные кровотечения встречаются редко. Заболевание у мужчин часто протекает бессимптомно, у женщин проявляется обильными менометроррагиями, геморрагический синдром может проявиться при травме или хирургических вмешательствах [29]. Диагностика основана на результатах определения плазменной активности FVII, диапазон нормальных значений которой составляет 70-120\%. При гипопроконвертинемии выраженность клинических проявлений слабо коррелирует с выраженностью дефицита FVII [31], а при проведении заместительной терапии rFVIIa лабораторные тесты (АЧТВ, ПВ, плазменная активность FVII) не коррелируют с его гемостатическим эффектом [32].

При дефищите FVIII (гемофилии A) отмечается снижение плазменной активности FVIII и удлинение АЧТВ при сохранении других показателей в пределах нормальных значений. Для тяжелой формы гемофилии А характерно снижение активности FVIII менее 1 \%, 


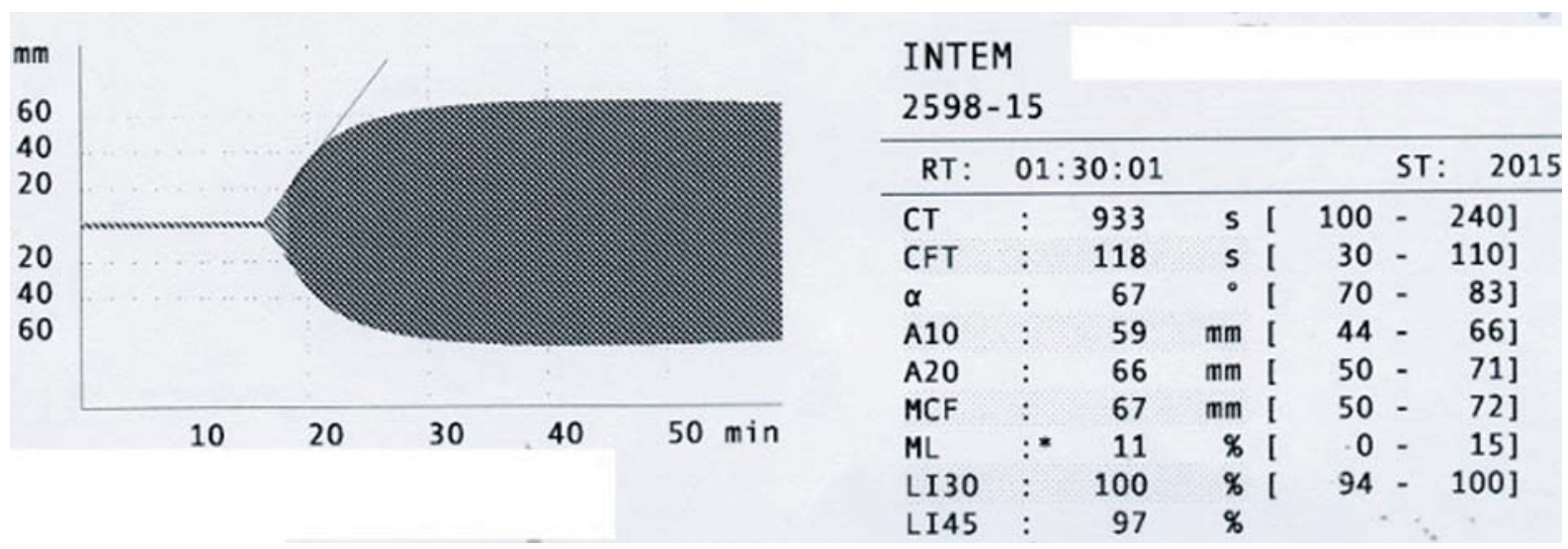

Рисунок 15. INTEM у у больного болезнью Хагемана до начала гемостатической терапии Figure 15. INTEM $M_{C T}$ in patient with Hageman's disease before hemostatic treatment

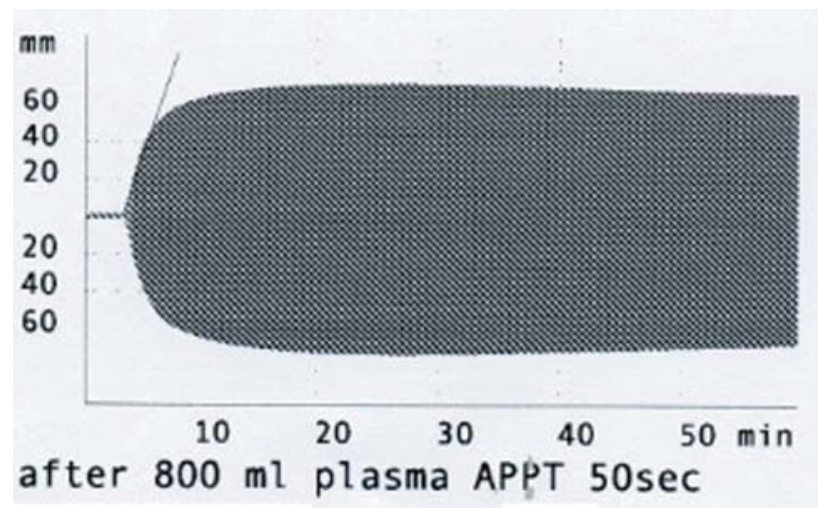

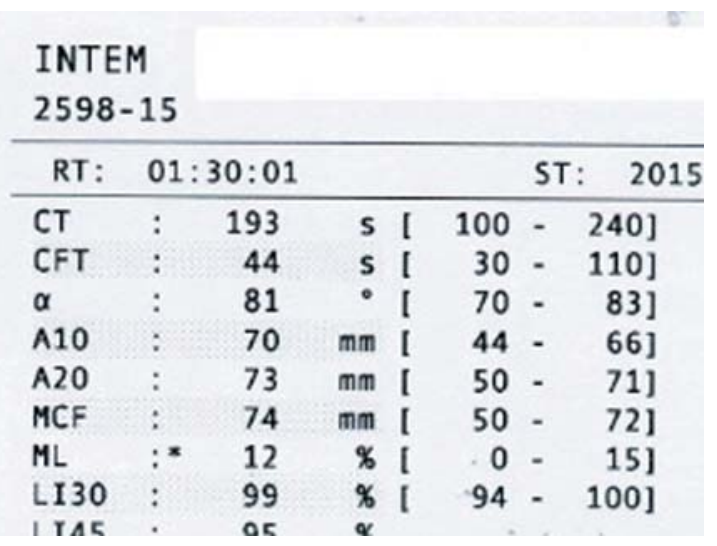

Рисунок 16. Нормализация INTEM СТ у больного болезнью Хагемана после трансфузии СЗП

Figure 16. INTEM ${ }_{C T}$ normalization in patient with Hageman's disease after FFP transfusion

для средней степени тяжести 1-5 \%, для легкой степени тяжести $>5 \%$ [23].

При дефиците FIX (гемофилии B) отмечается снижение плазменной активности FIX и удлинение АЧТВ. Диапазон нормальных значений плазменной активности FIX составляет 50-120 \%. Для тяжелой формы гемофилии В характерно снижение активности FIX менее $1 \%$, для средней степени тяжести $1-5 \%$, для легкой степени тяжести $>5 \%$ [23].

При дефищите FXI (гемофилия C) геморрагический синдром редко возникает спонтанно, как правило, после хирургических манипуляций, травм. Диапазон нормальных значений плазменной активности FXI составляет 70-120\%. Диагноз устанавливается на основании удлинения АЧТВ и сниженной плазменной активности FXI [29].

FXII (фактор Хагемана) активирует FXI, который затем триггирует фактор IX и приводит к тромбинопосредованному образованиюю фибрина [33]. Однако ведущая физиологическая роль FXII - участие в процессах фибринолиза. Поэтому дефицит FXII рассматривается как протромботическое состояние. В то время как геморрагические проявления случаются редко, обычно при инвазивных вмешательствах или операциях, нарушения гемостаза часто обнаруживают случайно при предоперационном скрининге. Диапазон нормальных значений плазменной активности FXI составляет 70-120 \% [29]. Удлинение АЧТВ регистрируется при снижении активности FXII в плазме крови ниже 42,5\% [34].

В основу методов определения активности факторов свертывания крови положено проведение тестов (FII, FV, FVII, FX) и/или АЧТВ (FVIII, FIX, FXI, FXII) в разбавленном исследуемом образце. При этом снижение активности факторов свертывания компенсируют внесением в инкубационную среду субстратной плазмы, не содержащей соответствующего фактора, но имеющей полноценную активность других факторов свертывания. Таким образом, активность анализируемых факторов в исследуемом образце оказывается единственной неизвестной величиной, определяющей скорость процесса свертывания. Количественное определение активности факторов проводят по калибровочному графику разведений плазмы-калибратора с аттестованной активностью соответствующего фактора [35].

Распространенным способом определения дефицита факторов свертывания является одностадийный клоттинговый метод исследования с использованием суб- 
стратных (дефицитных) образцов плазмы, лишенных одного из факторов свертывания крови [36]. Принцип метода заключается в определении промежутка времени после добавления стартового реактива, запускающего каскад свертывания плазмы по внутреннему или внешнему пути, в смесь субстратной (дефицитной) плазмы, в которой отсутствует исследуемый фактор, и исследуемой плазмы больного. Степень коррекции зависит от активности исследуемого фактора свертывания, поскольку активность других факторов свертывания в этой системе в норме. Активность дефицитного фактора в исследуемой плазме определяют по кривой разведения.

Двухстадийный клоттинговый метод определения активности факторов свертывания крови не требует использования субстратной дефицитной плазмы и не зависит от наличия активированного фактора свертывания в исследуемом образце [37]

Хромогенный метод определения активности факторов свертывания крови рекомендуется использовать только как ориентировочный и предпочтительно для оценки концентратов факторов свертывания, а не с диагностическими целями [35].

Концентрация факторов может также определяться иммуноферментным методом.

C помощью линейной регрессии показано [24], что имеется сильная ассоциация между выраженностью геморрагического синдрома и сниженной активностью FI и слабая ассоциация между выраженностью дефицита FV и FVII и клиническими проявлениями кровоточивости. Минимальная концентрация факторов, ниже которой у больных возникал геморрагический синдром, составила для фибриногена 1 г/л, для FV - 12 ед/дл, FVII - 25 ед/дл, FXI - 26 ед/дл, FXII - 31 ед/дл, а концентрация факторов в плазме крови, которая соответствует выраженному геморрагическому синдрому, составляет <10 ед/дл для FVII, $<25$ ед/дл для FXI, а для факторов свертывания FI, FV и FXII выраженный геморрагический синдром возникает, когда их концентрация в крови не определяется вообще [24].

Более того, ни один из вышеперечисленных методов нельзя отнести к методам point-of-care. Во многих стационарах нет условий, оборудования и специалистов для исследования активности факторов свертывания. В результате при выявлении нарушений в системе гемостаза, особенно если до обследования не известен диагноз, отменяются или откладываются инвазивные вмешательства либо лечение проводится без установленного диагноза и может оказаться неэффективным [38]. В то же время согласно приказу Министерства здравоохранения РФ от 15 ноября 2012 г. № 919н «Об утверждении Порядка оказания медицинской помощи взрослому населению по профилю “анестезиология и реаниматология” в в стандарт оснащения отделения анестезиологии-реанимации с палатами ре- анимации и интенсивной терапии входит тромбоэластограф или тромбоэластометр. В литературе описаны попытки использовать глобальные тесты исследования гемостаза для диагностики дефицита отдельных факторов свертывания [30]. Но большинство из них относится к применению теста генерации тромбина [39-41] и лишь единичные - к применению тромбоэластометрии [42].

Белорусские исследователи [43] изучили параметры тромбоэластометрии во время операции трансплантации печени, при которых отмечались изменения в крови содержания факторов свертывания (фибриногена, FII, FV, FVII, FVIII, FIX, FX, FXI, FXII). Авторы [43] отметили, что наибольшей диагностической эффективностью обладали следующие параметры: EXTEM $>80$ с и INTEM CT $_{2} 240$ с. Чувствительность изменения

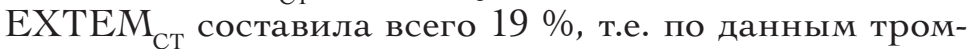
боэластометрии восполнение дефицита факторов будет проводиться лишь в каждом пятом случае, когда имеются показания согласно общепринятым рекомендациям (MHO >2,0). Чувствительность изменения INTEM $_{\text {CT }}>$ составила 51 \%. Однако авторы [43] не пытались по параметрам РОТЭМ дифференцировать дефицит отдельных факторов крови, а лишь оценивали их изменения в совокупности. Кроме того, в этом исследовании дефицит факторов был невыраженный, минимально факторы снижались через 15 минут после реперфузии (медианы FII 44 \%, FV 17 \%, FVII 29 \%, FIX 59 \%, FX 39 \%, FXI 56 \%, FXII 66 \%), т.е. их содержание было значительно больше, чем у больных с врожденным дефицитом, чем можно объяснить низкую чувствительность тестов.

Оценить возможность использования РОТЭМ для диагностики дефицита FV попытались T. Haas и соавт. [44]. Авторы смешивали плазму, дефицитную по FV, с нормальной человеческой плазмой (активность FV 96 \%) в разных пропорциях, чтобы получить плазму с активностью фактора $0,10,16,25,50$ и 100 \%. Затем исследовали каждое из разведений плазмы на ROTEM, чтобы оценить влияние разного количества фактора на СТ. Низкая активность FV ассоциировалась с удлинением СТ. Уменьшение активности FV со 100 до 25 \% сопровождалось удлинением СТ лишь с 50 до 65 с, но при уменьшении активности FV менее 10 \% период СТ удлинялся до 140 с и более.

Эти данные согласуются с результатами, полученными нами в настоящем исследовании: при смешивании цельной крови больного с дефицитом FV с дефицитной по FV плазмой сохранялось удлинение СT, а при смешивании с нормальной плазмой происходила нормализация СТ.

L. Spiezia и соавт. [42] исследовали возможность использования РОТЭМ для выявления нарушений гемостаза у 9 больных с дефицитом FV, используя для этого их цельную кровь и бедную тромбоцитами плазму. При постановке тестов с цельной кровью они выявили значимое удлинение СТ в трех стандартных тестах 
(INTEM, EXTEM, FIBTEM), в то время как показатель CFT был удлинен только в тесте INTEM и был неизмеряемым в тесте FIBTEM. При исследованиях in vitro c плазмой больных с дефицитом FV, бедной тромбоцитами, авторы выявили удлинение СТ и укорочение MCF в тестах INTEM, EXTEM и FIBTEM по сравнению с аналогичными показателями, выполненными с бедной тромбоцитами плазмой здоровых людей. Добавление при пробоподготовке к обоим образцам бедной тромбоцитами плазмы тромбоцитов больных либо тромбоцитов здоровых людей приводило к укорочению $\mathrm{CT}$, которое было более выражено при использовании тромбоцитов здоровых людей, причем СТ больше сокращался в EXTEM, чем в INTEM. Полученный эффект связан с тем, что $20 \%$ всего пула FV хранится в $\alpha$-гранулах тромбоцитов в частично активированной форме [45]. Аналогичные изменения на РОТЭМ зафиксировано было и в настоящей работе после трансфузии СЗП и концентрата тромбоцитов у больной с дефицитом фактора V при установке порт-системы.

Однако в работах по изучению влияния дефицита FV на показатели РОТЭМ исследователи не предлагали непосредственно методику диагностики дефицита фактора на основе РОТЭМ и не использовали ее для оценки эффективности и безопасности терапии. Особенностью представленного в настоящей работе клинического примера лечения больной дефицитом $\mathrm{FV}$ являлось то, что у больной в анамнезе были эпизоды венозных тромбозов после трансфузии свежезамороженной плазмы. Поэтому основной задачей лечения было компенсировать гипокоагуляцию таким образом, чтобы избежать гиперкоагуляции, сохраняя умеренную гипокоагуляцию, которая позволила бы выполнить оперативное вмешательство.

В нашем исследовании РОТЭМ использовали для диагностики и контроля за гемостатической терапией rFVIIа во время оперативного вмешательства у больной гипопроконвертинемией. В литературе мало сообщений об использовании вискоэластичных методов у больных гипопроконвертинемией. H.T.T. Tran и соавт. [46] обследовали с помощью модифицированных тестов РОТЭМ 12 больных с плазменной активностью FVII $<1 \%$. Как и в нашем исследовании, они выявили двукратное удлинение СТ в тесте с тканевым фактором (аналог теста EXTEM) по сравнению со здоровым контролем, при этом параметр MCF между группами не различался.

Описаны изменения РОТЭМ у больных гемофилией A и В [47], причем изменения параметров INTEM коррелируют с тяжестью гемофилии и выраженностью дефицита FVIII. Более того, отмечается, что использование вискоэластичных методов позволяет подобрать индивидуально дозы дефицитных факторов [47].

Данные по влиянию дефицита FXI фактора на INTEM были получены D. Dirkmann и соавт. [48]. Авторы использовали ROTEM для оценки влияния дефицита FXI на коагуляцию у пятилетней девочки с врожденным тяжелым дефицитом FXI, у которой отмечалось удлинение АЧТВ до 65-99 с, МНО составило 0,98 , концентрация фибриногена плазмы $-3,5$ г/л, плазменная активность FXI -2 \%. При обследовании с помощью РОТЭМ у нее были нормальные значения EXTEM $_{\text {Ст }}$ и более чем в три раза увеличен показатель INTEM $_{\text {CT }}(776$ c). При добавлении in vitro rFVIIa к пробе крови в концентрациях от 0,25 до 1 мкг/мл, что соответствует концентрации препарата в крови при внутривенном введении в дозе 15-70 мкг/кг массы тела. Было показано, что доза концентрации в крови 0,5 мкг/мл (что соответствует внутривенному введению rFVIIa в дозе 30 мкг/кг массы тела) столь же эффективно нор-

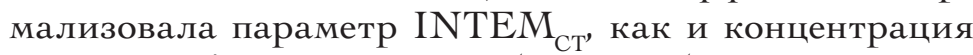
1 мкг/мл [49]. Имеется сообщение об использовании ROTEM для мониторинга терапии малыми дозами rFVIIa у больных с тяжелым дефицитом FXI при хирургических вмешательствах [49]. В нашем исследова-

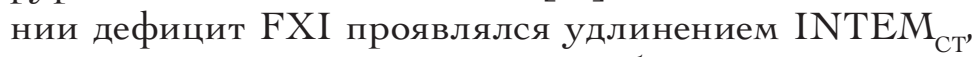
которое компенсировалось при добавлении стандартной плазмы в пробирку.

В литературе имеются лишь единичные сообщения о применении тромбоэластографии для диагностики изолированного дефицита FXII и мониторинга проводимой терапии у людей $[50,51]$ и животных [52]. Помимо того что при этом заболевании выявляется гипокоагуляция, дефицит FXII рассматривается как протромботическое состояние, ввиду того что FXII участвует в процессах фибринолиза. Преимущество использования РОТЭМ заключается в том, что, не измеряя непосредственно активности факторов, метод позволяет не только диагностировать нарушения гемостаза, но и контролировать эффективность и безопасность гемостатической терапии. Он позволяет дозировать гемостатическую терапию таким образом, чтобы удерживаться в «терапевтическом окне», в котором достигается приемлемый гемостаз, и в то же время не возникает гиперкоагуляция. Переход из состояния гипокоагуляции в гиперкогуляцию не всегда соответствует концентрации фактора в плазме, и лучше оценивать его функционально, с помощью РОТЭМ.

Ограничения исследования. Одним из ограничений исследования является небольшая выборка больных, поскольку это редко встречающиеся нарушения свертывания крови.

Другим ограничением метода может явиться сочетанный дефицит нескольких факторов, и хотя он также встречается крайне редко, для его диагностики будет необходимо усложнить алгоритм обследования.

Наконец, третьим ограничением может явиться наличие ингибиторов к факторам свертывания, когда представленный алгоритм не будет работать, поскольку в этих условиях добавление стандартной плазмы не приведет к нормализации активности факторов свертывания. 
Таким образом, с помощью РОТЭМ возможно определение дефицита отдельных факторов свертывания крови. После выявления удлинения СТ в ЕХTЕМ и/или INTEM, исключения действия гепарина и гипофибриногенемии, необходимо выполнить смешивание исследуемой свежей цитратной крови в соотношении

\section{Литература}

1. Saner F.H., Kirchner C. Monitoring and Treatment of Coagulation Disorders in End-Stage Liver Disease. Visc Med. 2016; 32(4): 241-8.

2. Дементьева И.И., Морозов Ю.А., Чарная М.А., Гончарова А.В. Технологии point of care в клинике неотложных состояний. Клиническая лабораторная диагностика. 2013; (7): 5-10.

3. Lang T., Bauters A., Braun S.L. et al. Multi-centre investigation on reference ranges for ROTEM thromboelastometry. Blood coagulation \& fibrinolysis: Int. J Haemost Thromb. 2005; 16(4): 301-10.

4. Butwick A.J., Goodnough L.T. Transfusion and coagulation management in major obstetric hemorrhage. Curr Opin Anaesthesiol. 2015; 28(3): 275-84.

5. Allard S., Green L., Hunt B.J. How we manage the haematological aspects of major obstetric haemorrhage. Br J Haematol. 2014; 164(2): 177-88.

6. Guasch E., Gilsanz F. Massive obstetric hemorrhage: Current approach to management. Med Intensiva. 2016; 40(5): 298-310.

7. Kander T., Larsson A., Taune V. et al. Assessment of Haemostasis in Disseminated Intravascular Coagulation by Use of Point-of-Care Assays and Routine Coagulation Tests, in Critically III Patients; A Prospective Observational Study. PloS One. 2016; 11(3): e0151202.

8. Wikkelsø A., Wetterslev J., Møller A.M., Afshari A. Thromboelastography (TEG) or rotational thromboelastometry (ROTEM) to monitor haemostatic treatment in bleeding patients: a systematic review with meta-analysis and trial sequential analysis. Anaesthesia. 2017; 72(4): 519-31. DOI: 10.1111/anae.13765

9. Meybohm P., Zacharowski K., Weber C.F. Point-of-care coagulation management in intensive care medicine. Crit care. 2013; 17(2): 218.

10. Curry N.S., Davenport R., Pavord S. et al. The use of viscoelastic haemostatic assays in the management of major bleeding. Br J Haematol. 2018; 182(6): 789-806

11. Korpallova B., Samos M., Bolek T. et al. Role of Thromboelastography and Rotational Thromboelastometry in the Management of Cardiovascular Diseases. Clin Appl Thromb Hemos. 2018; 24(8): 1199-207.

12. Zaky A. Thromboelastometry Versus Rotational Thromboelastography in Cardiac Surgery. Semin Cardiothorac Vasc Anesth. 2017; 21(3): 206-11.

13. Weber C.F., Görlinger K., Meininger D. et al. Point-of-Care Testing. Anesthesiology. 2012; 117(3): 531-47.

14. Görlinger K., Jambor C., Hanke A.A. et al. Perioperative Coagulation Management and Control of Platelet Transfusion by Point-of-Care Platelet Function Analysis. Transfus Med Hemother. 2007; 34(6): 396-411. DOI: $10.1159 / 000109642$

15. Rugeri L., Levrat A., David J.S. et al. Diagnosis of early coagulation abnormalities in trauma patients by rotation thrombelastography. J Thromb Haemost. 2007; 5(2): 289-95

16. Rizoli S., Min A., Perez Sanchez A. et al. In Trauma, Conventional ROTEM and TEG Results Are Not Interchangeable But Are Similar in Clinical Applicability. Mil Med. 2016; 181(5S): 117-26.

17. da Luz L.T., Nascimento B., Rizoli S. Thrombelastography (TEG®): practical considerations on its clinical use in trauma resuscitation. Scand J Trauma, Resusc Emerg Med. 2013; 21(1): 29 .
2:1 со стандартной плазмой и с дефицитной по одному из исследуемых факторов плазмой. Нормализация показателей РОТЭМ в пробе со стандартной плазмой и сохранение гипокоагуляции в пробе с дефицитной по фактору плазмой позволяет подтвердить дефицит фактора свертывания крови.

\section{References}

1. Saner F.H., Kirchner C. Monitoring and Treatment of Coagulation Disorders in End-Stage Liver Disease. Visc Med. 2016; 32(4): 241-8.

2. Dementiyeva I.I., Morozov Yu.A., Tcharnaya M.A., Gontcharova A.V. The point-of-care technologies in clinic of emergency states. Klinicheskaya laboratornaya diagnostika. 2013; (7): 5-10 (In Russian).

3. Lang T., Bauters A., Braun S.L. et al. Multi-centre investigation on reference ranges for ROTEM thromboelastometry. Blood coagulation \& fibrinolysis: Int. J Haemost Thromb. 2005; 16(4): 301-10.

4. Butwick A.J., Goodnough L.T. Transfusion and coagulation management in major obstetric hemorrhage. Curr Opin Anaesthesiol. 2015; 28 (3): 275-84.

5. Allard S., Green L., Hunt B.J. How we manage the haematological aspects of major obstetric haemorrhage. Br J Haematol. 2014; 164(2): 177-88.

6. Guasch E., Gilsanz F. Massive obstetric hemorrhage: Current approach to management. Med Intensiva. 2016; 40(5): 298-310.

7. Kander T., Larsson A., Taune V. et al. Assessment of Haemostasis in Disseminated Intravascular Coagulation by Use of Point-of-Care Assays and Routine Coagulation Tests, in Critically III Patients; A Prospective Observational Study. PloS One. 2016; 11(3): e0151202.

8. Wikkelsø A., Wetterslev J., Møller A.M., Afshari A. Thromboelastography (TEG) or rotational thromboelastometry (ROTEM) to monitor haemostatic treatment in bleeding patients: a systematic review with meta-analysis and trial sequential analysis. Anaesthesia. 2017; 72(4): 519-31. DOI: 10.1111/anae.13765

9. Meybohm P., Zacharowski K., Weber C.F. Point-of-care coagulation management in intensive care medicine. Crit care. 2013; 17(2): 218.

10. Curry N.S., Davenport R., Pavord S. et al. The use of viscoelastic haemostatic assays in the management of major bleeding. Br J Haematol. 2018;182(6): 789-806.

11. Korpallova B., Samos M., Bolek T. et al. Role of Thromboelastography and Rotational Thromboelastometry in the Management of Cardiovascular Diseases. Clin Appl Thromb Hemos. 2018; 24(8): 1199-207.

12. Zaky A. Thromboelastometry Versus Rotational Thromboelastography in Cardiac Surgery. Semin Cardiothorac Vasc Anesth. 2017; 21(3): 206-11.

13. Weber C.F., Görlinger K., Meininger D. et al. Point-of-Care Testing. Anesthesiology. 2012; 117(3): 531-47.

14. Görlinger K., Jambor C., Hanke A.A. et al. Perioperative Coagulation Management and Control of Platelet Transfusion by Point-of-Care Platelet Function Analysis. Transfus Med Hemother. 2007; 34(6): 396-411. DOl: 10.1159/000109642

15. Rugeri L., Levrat A., David J.S. et al. Diagnosis of early coagulation abnormalities in trauma patients by rotation thrombelastography. J Thromb Haemost. 2007; 5(2): 289-95

16. Rizoli S., Min A., Perez Sanchez A. et al. In Trauma, Conventional ROTEM and TEG Results Are Not Interchangeable But Are Similar in Clinical Applicability. Mil Med. 2016; 181(5S): 117-26.

17. da Luz L.T., Nascimento B., Rizoli S. Thrombelastography (TEG $®$ ): practical considerations on its clinical use in trauma resuscitation. Scand J Trauma, Resusc Emerg Med. 2013; 21(1): 29 . 
18. Gonzalez E., Moore E.E., Moore H.B. Management of Trauma-Induced Coagulopathy with Thrombelastography. Crit Care Clin. 2017; 33(1): 119-34.

19. Abuelkasem E., Lu S., Tanaka K. et al. Comparison between thrombelastography and thromboelastometry in hyperfibrinolysis detection during adult liver transplantation. Br J Anaesth. 2016; 116(4): 507-12.

20. Roullet S., Labrouche S., Mouton C. et al. Lysis Timer: a new sensitive tool to diagnose hyperfibrinolysis in liver transplantation. J Clin Pathol. 2019; 72(1): $58-65$.

21. Приказ Министерства здравоохранения и социального развития РФ от 13 апреля 2011 г. № 315н «Об утверждении Порядка оказания анестезиолого-реанимационной помощи взрослому населению».

22. Баркаган 3.С., Момот А.П. Диагностика и контролируемая терапия нарушений гемостаза. 3-е изд. М.: Ньюдиамед, 2008; 292.

23. Зозуля Н.И., Свирин П.В. Клинические рекомендации по диагностике и лечению редких коагулопатий: Наследственный дефицит факторов свертывания крови II, VII, Х. НГО. 2014; 35: 19.

24. Peyvandi F., Palla R., Menegatti M. et al. Coagulation factor activity and clinical bleeding severity in rare bleeding disorders: Results from the European Network of Rare Bleeding Disorders. J Thromb Haemost. 2012; 10 (4): 615-21.

25. Acharya S.S., Coughlin A., Dimichele D.M., North American Rare Bleeding Disorder Stud Group. Rare Bleeding Disorder Registry: deficiencies of factors II, V, VII, X, XIII, fibrinogen and dysfibrinogenemias. J Thromb Haemost. 2004; 2: 248-56.

26. Peyvandi F., Spreafico M. National and international registries of rare bleeding disorders. Blood Transfus. 2008; 6(Suppl. 2): 45-8.

27. Rezende S.M., Rodrigues S.H.L., Brito K.N.P. et al. Evaluation of a webbased registry of inherited bleeding disorders: A descriptive study of the Brazilian experience with HEMOVIDAweb Coagulopatias. OrphanetJ Rare Dis. 2017; 12(1): 1-7.

28. Abbonizio F., Hassan H.J., Riccioni R. et al. New data from the Italian National Register of Congenital Coagulopathies, 2016 Annual Survey. Blood Transfus. 2019; 1-8.

29. Мамаев А.Н. Коагулопатии. М.: ГЭОТАР-Медиа, 2012; 260.

30. Palla R., Peyvandi F., Shapiro A.D. Rare bleeding disorders: Diagnosis and treatment. Blood. 2015; 125(13): 2052-61.

31. Herrmann F.H., Wulff K., Auberger K. et al. Molecular biology and clinical manifestation of hereditary factor VII deficiency. Semin Thromb Hemost. 2000; 26(4): 393-400.

32. Martinowitz U., Michaelson M. Guidelines for the use of recombinant activated factor VII (rFVIla) in uncontrolled bleeding: a report by the Israeli multidisciplinary rFVlla task force. J Thromb Haemost. 2005; 3(4): 640-8.

33. Simão F., Feener E.P. The effects of the contact activation system on hemorrhage. Front Med. 2017; 4: 1-10.

34. Bachler M., Niederwanger C., Hell T. et al. Influence of factor XII deficiency on activated partial thromboplastin time (aPTT) in critically ill patients. J Thromb Thrombolysis. 2019. DOI: 10.1007/s11239-019-01879-w

35. Долгов В., Свирин ПВ. Лабораторная диагностика нарушений гемостаза. М.-Тверь: Триада; 2005: 227.

36. Langdell R., Wagner R., Brinkhous K. Effect of antihemophilic factor on onestage clotting tests; a presumptive test for hemophilia and a simple one-stage antihemophilic factor assy procedure. J Lab Clin Med. 1953; 41 (4): 637-47.

37. Biggs R., Eveling J., Richards G. The Assay of Antihaemophilic-Globulin Activity. Br J Haematol. 1955; 1(1): 20-34.

38. Лубнин А.Ю., Коновалов А.Н., Ласунин Н.В. и др. Тяжелые послеоперационные интракраниальные геморрагические осложнения у нейрохирургическо-
18. Gonzalez E., Moore E.E., Moore H.B. Management of Trauma-Induced Coagulopathy with Thrombelastography. Crit Care Clin. 2017; 33(1): 119-34.

19. Abuelkasem E., Lu S., Tanaka K. et al. Comparison between thrombelastography and thromboelastometry in hyperfibrinolysis detection during adult liver transplantation. Br J Anaesth. 2016; 116(4): 507-12.

20. Roullet S., Labrouche S., Mouton C. et al. Lysis Timer: a new sensitive tool to diagnose hyperfibrinolysis in liver transplantation. J Clin Pathol. 2019; 72 (1): $58-65$.

21. The Order of the Ministry of Health and Social Development of the Russian Federation of April 13, 2011 № 315n "On approval of the provision of anesthesia and resuscitation care to the adult population" (In Russian).

22. Barkagan Z.S., Momot A.P. Diagnostics and management of hemostasis disorders. 3d edition. Moscow. Newdiamed; 2008; 292:25, 103-13 (In Russian).

23. Zozulia N.I, Svirin P.V. Clinical practice guidelines for diagnostics and management of rare coagulopathy: inherited coagulation factors deficiencies. National hematology society. 2014; 35: 19 (In Russian).

24. Peyvandi F., Palla R., Menegatti M. et al. Coagulation factor activity and clinical bleeding severity in rare bleeding disorders: Results from the European Network of Rare Bleeding Disorders. J Thromb Haemost. 2012; 10(4): 615-21.

25. Acharya S.S., Coughlin A., Dimichele D.M., North American Rare Bleeding Disorder Stud Group. Rare Bleeding Disorder Registry: deficiencies of factors II, V, VII, X, XIII, fibrinogen and dysfibrinogenemias. J Thromb Haemost. 2004; 2 : $248-56$

26. Peyvandi F., Spreafico M. National and international registries of rare bleeding disorders. Blood Transfus. 2008; 6(Suppl. 2): 45-8.

27. Rezende S.M., Rodrigues S.H.L., Brito K.N.P. et al. Evaluation of a webbased registry of inherited bleeding disorders: A descriptive study of the Brazilian experience with HEMOVIDAweb Coagulopatias. OrphanetJ Rare Dis. 2017; 12(1): 1-7.

28. Abbonizio F., Hassan H.J., Riccioni R. et al. New data from the Italian National Register of Congenital Coagulopathies, 2016 Annual Survey. Blood Transfus. 2019; 1-8.

29. Mamaev AN. Coagulopathies. Moscow: GEHOTAR-Media, 2012; 260 (In Russian).

30. Palla R., Peyvandi F., Shapiro A.D. Rare bleeding disorders: Diagnosis and treatment. Blood. 2015; 125(13): 2052-61.

31. Herrmann F.H., Wulff K., Auberger K. et al. Molecular biology and clinical manifestation of hereditary factor VII deficiency. Semin Thromb Hemost. 2000; 26(4): 393-400.

32. Martinowitz U., Michaelson M. Guidelines for the use of recombinant activated factor VII (rFVIla) in uncontrolled bleeding: a report by the Israeli multidisciplinary rFVIla task force. J Thromb Haemost. 2005; 3(4): 640-8.

33. Simão F., Feener E.P. The effects of the contact activation system on hemorrhage. Front Med. 2017; 4: 1-10.

34. Bachler M., Niederwanger C., Hell T. et al. Influence of factor XII deficiency on activated partial thromboplastin time (aPTT) in critically ill patients. J Thromb Thrombolysis. 2019. DOI: 10.1007/s11239-019-01879-w

35. Dolgov V., Svirin P.V. Laboratory diagnostics of hemostasis disorders. Moscow - Tver': Triada, 2005; 227 (In Russian).

36. Langdell R., Wagner R., Brinkhous K. Effect of antihemophilic factor on onestage clotting tests; a presumptive test for hemophilia and a simple one-stage antihemophilic factor assy procedure. J Lab Clin Med. 1953; 41(4):637-47.

37. Biggs R., Eveling J., Richards G. The Assay of Antihaemophilic-Globulin Activity. Br J Haematol. 1955; 1 (1): 20-34.

38. Lubnin A.Y., Konovalov A.N., Lasunin N.V. et al. Severe postoperative intracranial hemorrhagic complications in a neurosurgical patient with von Wille- 
го больного с не диагностированной до операции болезнью Виллебранда (клиническое наблюдение и обзор литературы). Вопросы нейрохирургии» имени Н.Н. Бурденко. 2018; 82(3): 56-65. DOI: 10.17116/neiro201882356

39. Rugeri L., Quélin F., Chatard B. et al. Thrombin generation in patients with factor XI deficiency and clinical bleeding risk. Haemophilia. 2010; 16(5): 771-7. 40. Hemker H., Giansily M., Peyvandi F. et al. The Thrombogram in Rare Inherited Coagulation Disorders: Its Relation to Clinical Bleeding. Thromb Haemost. 2018; 88(10): 576-82.

41. Van Geffen M., Menegatti M., Loof A. et al. Retrospective evaluation of bleeding tendency and simultaneous thrombin and plasmin generation in patients with rare bleeding disorders. Haemophilia. 2012; 18(4): 630-8.

42. Spiezia L., Radu C., Campello E. et al. Whole blood rotation thromboelastometry (ROTEM $(\mathbb{R})$ in nine severe factor $\mathrm{V}$ deficient patients and evaluation of the role of intraplatelets factor V. Haemophilia. 2012; 18(3): 463-8.

43. Минов А.Ф., Дзядзько А.М., Руммо О.О. Тромбоэластометрические критерии коррекции нарушений гемостаза при трансплантации печени. Анестезиология и реаниматология. 2012; 57(2): 35-41.

44. Haas T., Cushing M.M., Asmis L.M. Influence of Factor V Deficiency on ROTEM® Clotting Time. Blood. 2014; 124(21): 5039.

45. Chakri G., Yates S.G., Rambally S., Sarode R. Transfusion management of factor $V$ deficiency: three case reports and review of the literature. Transfusion. 2016; 56(7): 1745-9.

46. Tran H.T.T., Tiønnfiord G.E., Holme P.A. Use of thromboelastography and thrombin generation assay to predict clinical phenotype in patients with severe FVII deficiency. Haemophilia. 2013; 20(1): 141-6.

47. Nogami K. The utility of thromboelastography in inherited and acquired bleeding disorders. Br J Haematol. 2016; 174(4): 503-14.

48. Dirkmann D., Hanke A.A., Görlinger K., Peters J. Perioperative use of modified thrombelastography in factor XI deficiency: A helpful method to assess drug effects. Acta Anaesthesiol Scand. 2007; 51(5): 640-3. DOI: 10.1111/i.13996576.2007.01284.x

49. Riddell A., Abdul-Kadir R., Pollard D. et al. Monitoring low dose recombinant factor VIla therapy in patients with severe factor XI deficiency undergoing surgery. Thromb Haemost. 2011; 106(9): 521-7.

50. Pivalizza E.G. Perioperative use of the Thrombelastograph $®$ in patients with inherited bleeding disorders. J Clin Anesth. 2003; 15(5): 366-70.

51. Pluthero F.G., Ryan C., Williams S. et al. Decreased in vitro thrombin generation and clot stability in human FXII-null blood and plasma. Br J Haematol. 2011; 152(1): 111-2.

52. Blois S.L., Holowaychuk M.K., Wood R.D. Evaluation of thromboelastography in two factor XII-deficient cats. JFMS Open Rep. 2015; 1 (1): 205511691558502. DOI: $10.1177 / 2055116915585025$ brand disease not diagnosed before surgery (a case report and literature review. Vopr Nejrokhirurgii Im NN Burdenko. 2018; 82(3): 56-65 (In Russian). DOI: 10.17116/neiro201882356

39. Rugeri L., Quélin F., Chatard B. et al. Thrombin generation in patients with factor XI deficiency and clinical bleeding risk. Haemophilia. 2010; 16(5): 771-7. 40. Hemker H., Giansily M., Peyvandi F. et al. The Thrombogram in Rare Inherited Coagulation Disorders: Its Relation to Clinical Bleeding. Thromb Haemost. 2018; 88(10): 576-82.

41. Van Geffen M., Menegatti M., Loof A. et al. Retrospective evaluation of bleeding tendency and simultaneous thrombin and plasmin generation in patients with rare bleeding disorders. Haemophilia. 2012; 18(4): 630-8.

42. Spiezia L., Radu C., Campello E. et al. Whole blood rotation thromboelastometry (ROTEM $\otimes)$ in nine severe factor $V$ deficient patients and evaluation of the role of intraplatelets factor V. Haemophilia. 2012; 18(3): 463-8.

43. Minov A.F., Dzyadzko A.M., Rummo O.O. The tromboelastometric criteria of hemostasis disorders correction during liver transplantation. Anesteziologiya i reanimatologiya. 2012; 57(2): 35-41 (In Russian).

44. Haas T., Cushing M.M., Asmis L.M. Influence of Factor V Deficiency on ROTEM® Clotting Time. Blood. 2014; 124(21): 5039.

45. Chakri G., Yates S.G., Rambally S., Sarode R. Transfusion management of factor $V$ deficiency: three case reports and review of the literature. Transfusion. 2016; 56(7): 1745-9.

46. Tran H.T.T., Tiønnfiord G.E., Holme P.A. Use of thromboelastography and thrombin generation assay to predict clinical phenotype in patients with severe FVII deficiency. Haemophilia. 2013; 20(1): 141-6.

47. Nogami K. The utility of thromboelastography in inherited and acquired bleeding disorders. BrJ Haematol. 2016; 174(4): 503-14.

48. Dirkmann D., Hanke A.A., Görlinger K., Peters J. Perioperative use of modified thrombelastography in factor XI deficiency: A helpful method to assess drug effects. Acta Anaesthesiol Scand. 2007; 51(5): 640-3. DOI: 10.1111/i.13996576.2007.01284.x

49. Riddell A., Abdul-Kadir R., Pollard D. et al. Monitoring low dose recombinant factor VIla therapy in patients with severe factor XI deficiency undergoing surgery. Thromb Haemost. 2011; 106(9): 521-7.

50. Pivalizza E.G. Perioperative use of the Thrombelastograph $₫$ in patients with inherited bleeding disorders. J Clin Anesth. 2003; 15(5): 366-70.

51. Pluthero F.G., Ryan C., Williams S. et al. Decreased in vitro thrombin generation and clot stability in human FXII-null blood and plasma. Br J Haematol. 2011; 152(1): 111-2.

52. Blois S.L., Holowaychuk M.K., Wood R.D. Evaluation of thromboelastography in two factor XII-deficient cats. JFMS Open Rep. 2015; 1 (1): 205511691558502. DOI: $10.1177 / 2055116915585025$ 


\section{Информация об авторах}

Галстян Геннадий Мартинович*, доктор медицинских наук, заведующий отделением реанимации и интенсивной терапии ФГБУ «Национальный медицинский исследовательский центр гематологии» Министерства здравоохранения Российской Федерации,

e-mail: gengalst@gmail.com, тел.: +7 (495) 612-48-59;

ORCID: http://orcid.org/0000-0001-8818-8949

Полеводова Олеся Алексеевна, врач-анестезиолог-реаниматолог отделения реанимации и интенсивной терапии ФГБУ «Национальный медицинский исследовательский центр гематологии» Министерства здравоохранения Российской Федерации, e-mail: polevodova_md@mail.ru, тел.: +7 (495) 612-48-59;

ORCID: https://orcid.org/0000-0002-7783-5861

Яковлева Елена Владимировна, кандидат медицинских наук, врач-гематолог отдела коагулопатий ФГБУ «Национальный медицинский исследовательский центр гематологии» Министерства здравоохранения Российской Федерации,

e-mail: hemophilia2012@mail.ru, тел.: +7 (495) 612-29-12;

ORCID: https://orcid.org/0000-0002-6991-7437

Щекина Антонина Евгеньевна, аспирант отделения реанимации и интенсивной терапии ФГБУ «Национальный медицинский исследовательский центр гематологии» Министерства здравоохранения Российской Федерации,

e-mail: shekina_ae@mail.ru, тел.: +7 (495) 912-48-59;

ORCID: https://orcid.org/0000-0002-7916-2322

\section{* Автор, ответственный за переписку}

Поступила: 19.08.2019

Принята к печати: 12.09.2019

\section{Information about the authors}

Gennady M. Galstyan*, Dr. Sci. (Med.), Head of the Resuscitation and Intensive Care Unit, National Research Center for Hematology, e-mail: gengalst@gmail.com, tel.: +7 (495) 612-48-59;

ORCID: http://orcid.org/0000-0001-8818-8949

Olesya A. Polevodova, Intensivist, Resuscitation and Intensive Care Unit, National Research Center for Hematology,

e-mail: polevodova_md@mail.ru, tel.: +7 (495) 612-48-59;

ORCID: https://orcid.org/0000-0002-7783-5861

Elena V. Yakovleva, Cand. Sci. (Med.), Hematologist, Coagulopathy Department, National Research Center for Hematology,

e-mail: hemophilia2012@mail.ru, tel.: +7 (495) 612-29-12;

ORCID: https://orcid.org/0000-0002-6991-7437

Antonina E. Shchekina, Postgraduate Researcher, Resuscitation and Intensive Care Unit, National Research Center for Hematology, e-mail: shekina_ae@mail.ru, tel.: +7 (495) 912-48-59;

ORCID: https://orcid.org/0000-0002-7916-2322 